Economia e Sociedade, Campinas, Unicamp. IE.

http://dx.doi.org/10.1590/1982-3533.2016v25n3art2

\title{
Crescimento, ciclo econômico, mudança tecnológica e financiamento *
}

\author{
Hermes Yukio Higachi * \\ Gilberto Tadeu Lima ${ }^{* * *}$ \\ João Basilio Pereima *****
}

\begin{abstract}
Resumo
Este artigo analisa as relações entre o crescimento, o ciclo econômico, e o financiamento da firma em um ambiente inovativo. Este processo é analisado com a utilização de um modelo baseado em agentes, com 100 firmas interagindo entre si e com um sistema bancário, onde os regimes de financiamento do tipo hedge, especulativo e Ponzi são propriedades macroeconômicas emergentes da economia. Dois regimes tecnológicos são comparados: baixo e alto desenvolvimento tecnológico. A emergência de ciclos ou crises não está predeterminada, mas decorre da natureza complexa das interações no nível agente-agente e no nível agente-ambiente macro. A construção de uma teoria integrada do ciclo e do crescimento, da inovação e do financiamento, é possível desde que se recorra a uma abordagem baseada em agentes heterogêneos, uma vez que o ciclo ou crescimento não é um atributo exclusivo do agente (firma) ou do ambiente macro, mas sim da interação constante entre todas as partes do sistema. Ao final o artigo realiza uma análise econométrica sobre dados gerados artificialmente, como forma de mostrar que, mesmo com o uso de equações em diferenças finitas, com causalidades temporais pré-definidas, os resultados emergentes produzem relações de causalidade bidirecionais no sentido de Granger entre a inovação, o grau de fragilidade financeira, o crescimento e o ciclo econômico, tal como tem sido reconhecido na literatura empírica.
\end{abstract}

Palavras chave: Crescimento econômico; Ciclo; Tecnologia; Finanças; Complexidade.

\section{Abstract \\ Growth, business cycle, technological change, financing, complexity}

This paper investigates the relationship between economic growth, business cycle and the financing of firms in an innovative environment. The process is investigated using an agent-based model featuring 100 firms that interact with each other and the banking system, which generates hedge, speculative and Ponzi financing regimes as emergent properties of the economy. Two technological regimes are compared: low and high technological development. The emergence of cycles is not predetermined, but rather stems from the complex nature of the interactions at the agent-agent and agent-macro environment levels. The building of an integrated theory of cycle and growth, innovation and financing

* Artigo recebido em 22 de março de 2015 e aprovado em 5 de julho de 2016.

*** Professor no Departamento de Economia da Universidade Estadual de Ponta Grossa (UEPG), Ponta Grossa, PR, Brasil. E-mail: hhigachi@uepg.br.

*** Professor no Departamento de Economia da Faculdade de Economia, Administração e Contabilidade da Universidade de São Paulo (FEA-USP), São Paulo, SP, Brasil. Agradecimentos ao Conselho Nacional de Desenvolvimento Científico e Tecnológico( $(\underline{\mathrm{CNPq}})$ por bolsa de produtividade em pesquisa. E-mail: giltadeu@usp.br.

**** Professor no Departamento de Economia da Universidade Federal do Paraná (UFPR), Curitiba, PR, Brasil. E-mail: joãobasilio@ufpr.br. 
can be carried out by following an agent-based approach, as economic growth and business cycles are not exclusive attributes of the agent (firm) or the macroeconomic environment alone, but rather result from the continuing interactions among all of the constituent parts of the system. The paper also carries out an econometric analysis of the data generated artificially by the simulations. It is shown that, even if the model is specified with finite difference equations, which imply predetermined temporal causality relations, the emergent results generate bidirectional causality (in the sense of Granger) between innovation, financial fragility, business cycles and economic growth, as is amply supported by the existing empirical evidence.

Keywords: Technological change; Finance; Cycle; Economic growth; Complexity.

JEL O11, O16, O42.

\section{Introdução}

A interação entre o crescimento e o ciclo econômico, o progresso tecnológico, e o financiamento da firma e da pesquisa tem sido intensamente estudada na ciência econômica, tanto do ponto de vista teórico quanto empírico. Não há consenso sobre as relações de causalidade entre o crescimento ou ciclo e as variáveis financeiras, embora um número crescente de autores se refiram às relações contemporâneas entre o crescimento e o desenvolvimento de mercados financeiros. O problema torna-se mais difícil de analisar, quando uma quarta variável, a inovação, é incluída na análise. Com efeito, a teoria macroeconômica tem analisado separadamente as relações entre o ciclo ou o crescimento e a inovação, e entre o ciclo ou o crescimento e o sistema financeiro. Há poucos estudos e modelos analisando conjuntamente as quatro variáveis.

Uma vasta literatura tem sugerido que há uma forte relação entre as finanças e o crescimento(Levine, 2005), embora seja controverso estabelecer uma relação de causalidade específica, desde que as interações são bidirecionais. A interação entre as finanças e o crescimento, embora negada ou minimizada por alguns (e.g., McKinnon, 1973) ${ }^{1}$, ou relegada a um papel secundário e subordinada à atividade industrial por outros (e.g., Robinson, 1962), é reconhecida por muitos e em geral está associada aos trabalhos de Goldsmith (1969), Lucas (1988) e Shaw (1973), os quais afirmam existir um forte conexão entre a superestrutura financeira de um país e sua real infraestrutura. Esta conexão, segundo Goldsmith (1969,p. 400), "acelera o crescimento econômico e melhora a performance econômica em uma extensão que facilita a migração de fundos para o melhor uso, isto é, para os lugares da economia onde os fundos irão produzir as taxas de retorno sociais mais altas". Dados entre 1860-1963 mostrados por Goldsmith evidenciam uma tendência secular de aumento na proporção de ativos das instituições financeiras em relação ao produto nacional bruto para os países desenvolvidos e menos desenvolvidos. Mas, como o autor observa, é difícil "confiar na direção do mecanismo causal, ou seja, de decidir se

(1) Em conhecido artigo Lucas afirmou que "In general, I believe that the importance of financial matters is very badly over-stressed in popular and even much professional discussion and so am not inclined to be apologetic for going to the other extreme" (Lucas, 1988, p. 6). 
fatores financeiros foram responsáveis pela aceleração do desenvolvimento econômico ou se o desenvolvimento financeiro reflete o crescimento econômico cujo impulso deve ser buscado em outro lugar" (p. 48).

Outras evidências positivas, utilizando-se de recursos econométricos, são fornecidas por Jung (1986). Analisando um grupo de 56 países Jung mostra que a causalidade (no sentido Granger) ocorre em ambos os sentidos. Finalmente, os estudos de casos históricos, como os realizadas por Cameron (1967), salientaram a importância de fatores financeiros no desenvolvimento econômico de vários países europeus.

Em geral, a literatura macroeconômica afirma que a existência de instrumentos financeiros, mercados e instituições melhoram a gestão de riscos e contribuem para reduzir os efeitos de assimetria de informações e de custos de transações, mudando os incentivos e as restrições com que se deparam os agentes econômicos (Merton, 1995; Merton; Bodie, 1995). E não apenas isso, os intermediários financeiros podem produzir um melhor conjunto de informações, compartilhar riscos, melhorar a alocação de recursos e impulsionar com isso o crescimento (Greenwood; Jovanovic, 1990).

Além das relações gerais entre as finanças e o crescimento, uma literatura específica e complementar tem analisado a interação entre as finanças e a atividade inovativa, mais diretamente. De acordo com Arrow (1962) e De La Fuente e Marin (1996), em um ambiente sujeito a incerteza, como é a atividade inovadora, as firmas engajadas nesta atividade se beneficiarão se puderem recorrer a um mercado financeiro capaz de prover fundos para os projetos de pesquisa e desenvolvimento. Conforme o sistema financeiro se torna mais e mais eficiente em alocar recursos à pesquisa, selecionando os projetos mais atraentes e monitorando e compartilhando riscos, os efeitos positivos sobre o crescimento econômico se fazem sentir. O sistema financeiro melhora a alocação de crédito entre os produtores de tecnologia, com consequências positivas sobre o crescimento econômico. De acordo com esta literatura, a principal contribuição da intermediação financeira é a possibilidade do mercado lidar com o problema de seleção adversa em mercados de crédito ${ }^{2}$.

Uma explicação adicional sobre a conexão entre as finanças e a inovação é apresentada por King e Levine (1993). Os autores discutem o financiamento e a inovação em um modelo de crescimento endógeno em que os sistemas financeiros avaliam os potenciais empresários e mobilizam a poupança para financiar as atividades mais promissoras em termos de melhoria de produtividade. A atividade bancária diversifica os riscos associados às atividades inovadoras e seleciona os projetos de inovação com os mais altos lucros esperados ao invés de selecionar os projetos com menor valor, que utilizam os métodos de produção existentes e portanto

(2) Outros trabalhos nesta linha de investigação são Bencivenga e Smith (1991); Levine (1991); Boyd e Smith (1992) e Saint-Paul (1992). 
são mais seguros. Na mesma direção, e de forma até mais forte, Galetovic (1996)argumenta que em uma economia onde o crescimento depende da especialização por inovação, o crescimento econômico sustentado pode não iniciar se não surgir simultaneamente um mercado de intermediação financeira. A intermediação financeira, para o autor, é uma condição necessária para o crescimento sustentado. Para Morales (2003),na mesma linha de raciocínio, a intermediação financeira pode reduzir a incidência de risco moral por parte das firmas engajadas em pesquisa. A atividade financeira promove o crescimento porque ela aumenta a produtividade da pesquisa. E assim, ainda segundo Morales, os subsídios ao setor financeiro podem ter efeitos maiores do que subsídios dirigidos diretamente às firmas, uma vez que as firmas incorrem em risco moral no uso dos incentivos ao passo que o sistema financeiro não. No entanto, diante do risco moral, não completamente eliminado pela atividade financeira, os subsídios crescentes podem até mesmo reduzir a taxa de crescimento.

O sistema financeiro, tal como tem sido tratado na literatura de crescimento e dos ciclos, exerce um efeito inequivocamente positivo sobre o crescimento econômico. Para que isso aconteça, geralmente se assume que as atividades financeiras sempre são capazes de gerenciar corretamente o risco de crédito e canalizar os investimentos para as melhores oportunidades de retorno. No entanto, a história econômica é repleta de episódios de crises financeiras com impactos negativos sobre o crescimento econômico. Como observam Brown, Fazzari e Petersen (2009), se firmas inovadoras demandarem fundos para o financiamento de projetos de inovação e se houver alguma forma de restrição na oferta destes fundos, então uma mudança na disponibilidade de recursos financeiros poderá ter consequências macroeconômicas significativas. A expansão na oferta de fundos conduz a uma expansão de $\mathrm{P} \& \mathrm{D}$, enquanto que, por sua vez, as contrações causam sua queda ${ }^{3}$.

Esta literatura macroeconômica, teórica e empírica, tem enfatizado as relações diretas entre o crescimento ou ciclo e o sistema financeiro, em geral a partir de modelos estruturais e econométricos agregados. Embora detectado ao nível macro econômico a origem da instabilidade financeira em um ambiente de forte concorrência tecnológica permanece um desafio teórico. Neste artigo, propõe-se que a solução para o desafio teórico consiste em uma integração dos planos micro e macroeconômicos a partir de modelos baseados em agentes heterogêneos e

(3) Comentando dados da economia americana, os autores descrevem que "...the U.S. has recently experienced a finance-driven cycle in R\&D. From 1994 to 2004, there was a dramatic boom, and subsequent decline, in $R \& D$ : the ratio of privately financed industrial $R \& D$ to GDP rose from $1.40 \%$ in 1994 to an all-time high of $1.89 \%$ in 2000 before declining to an average of 1.70\% from 2002 to 2004, according to a survey from the National Science Foundation. (...) From 1994 to 2004, there was also a dramatic boom and bust in both cash flow and external equity finance in these industries. Internal finance (cash flow) for publicly traded firms increased from $\$ 89$ billion in 1993 to \$231 billion in 2000, and then collapsed in 2001 and 2002. External public equity finance rose from \$24 billion in 1998 to $\$ 86$ billion in 2000, but then plummeted $62 \%$ in 2001" (p. 153). 
evolucionários, desde que são mais flexíveis do que os modelos de equilíbrio baseados em agentes representativos com expectativas racionais para tratar de interações complexas e dos efeitos de feedback positivos e negativos. A emergência de instabilidade ou fragilidade financeira e de ciclos econômicos endógenos como resultado de decisões e/ou interações complexas de agentes heterogêneos foi tratada formalmente por Gallegati, Giulioni e Kichiji (2006)e Lima e Freitas (2007a; 2007b).

Em Gallegati, Giulioni e Kichiji (2006) é formulado uma estrutura de economia em que os agentes heterogêneos (100 firmas e um banco monopolista) interagem no mercado financeiro, gerando uma dinâmica agregada complexa. Cada firma produz um bem homogêneo por meio de uma tecnologia com retornos constantes de escala, e o estoque de capital é o único insumo de produção com produtividade constante e distribuída de forma homogênea entre as firmas. Em cada período $t$, a firma escolhe quanto produzir, - e portanto quanto investir em estoque de capital-, com base na taxa de juros e em sua fragilidade financeira. Para os autores a fragilidade financeira é determinada pela "razão de ativos". . A taxa de acumulação de capital depende positivamente da "razão de ativos" da firma (i.e. quanto menor o seu grau de fragilidade financeira) e negativamente da taxa de juros. Por outro lado, as firmas vendem seu produto em um preço incerto devido ao seu conhecimento limitado das condições de mercado, assim o preço de venda da firma é uma variável aleatória com valor esperado igual ao preço de mercado desconhecido pela firma e com variância finita. A receita de vendas é igual ao preço relativo multiplicado pelo produto da firma em cada período $t$. O preço relativo é uma variável aleatória positiva com valor esperado igual a 1 e variância finita, e segue uma distribuição uniforme no intervalo [0,2]. Para os autores a estratégia de fixação de preços da firma é exógena e aleatória, dentro do intervalo [0,2]. A firma pode ir a falência se sua riqueza líquida tornar-se negativa, sendo que a riqueza líquida é igual a riqueza líquida do período anterior mais lucros retidos. Como a oferta de crédito do banco é proporcional a seu estoque de ativos que aumenta se os lucros passados forem positivos, há um canal entre o estoque de ativos da firma e do banco que pode gerar um efeito dominó. O processo pode funcionar de forma inversa, em caso de resultados negativos. Se uma firma de grande porte ir à falência, pode causar a redução dos lucros do banco monopolista e de seu estoque de ativos. Como resultado, a oferta de crédito pode sofrer redução e a taxa de juros aumentar, deprimindo a demanda de crédito para o investimento e para a produção, e se as falências forem propagadas na economia, o mercado financeiro pode sofrer um colapso e o mercado real uma flutuação pró-cíclica.

(4) A razão de ativos é calculada como:

$$
\text { Razão de Ativos }{ }_{t}=\frac{\text { estoque de ativos }_{t}}{\text { estoque de ativos }{ }_{t}+\text { estoque de débitos acumulados pela firma }{ }_{t}}
$$


Em suma, as principais limitações teóricas do modelo deGallegati, Giulioni e Kichiji (2006) são: (i) embora seja um modelo baseado em agentes, o grau de interação entre eles é muito baixo: não há mecanismos de interação entre as firmas para ajustar o mark up e fixar preços; não há interações que permitam ou conduzam à competição tecnológica entre as firmas; a demanda não é um processo adaptativo em função do ciclo de mercado; (ii) as interações entre as firmas são indiretas por meio do mercado financeiro, não havendo interações diretas entre as firmas no mercado de bens intermediários ou finais; (iii) a heterogeneidade é caracterizada pelos regimes de financiamento de firmas (hedge, especulativo e ponzi) e pelo tamanho de firmas (pequeno, médio e grande), porém não há heterogeneidade na dimensão tecnológica; e (iv) a origem da instabilidade ou grau de fragilidade financeira consiste em pequenos choques idiossincráticos no nível de preços das firmas.

Por sua vez, Lima e Freitas (2007b) elaboram um modelo de produção baseado em agentes heterogêneos, no qual a oferta de moeda de crédito por um sistema bancário adaptativo e o fluxo de caixa de firmas heterogêneas são modelados como fenômenos co-evolucionários. A distribuição de regimes de financiamento (hedge, especulativo e ponzi) entre as firmas, ou o grau de robustez financeira do sistema, emerge como uma ordem espontânea. No modelo há três tipos de agentes: os 5000 consumidores, as 100 firmas e um banco monopolista. Ao contrário do modelo de Gallegati, Giulioni e Kichiji (2006), a oferta de moeda de crédito em qualquer período é endógena e determinada pela demanda de crédito pelas firmas, enquanto que a taxa nominal de juros é fixada por um sistema bancário adaptativo por meio de uma regra simples e adaptativa: um mark up sobre uma taxa básica de juros da economia determinada por uma autoridade monetária exógena. Um aumento na taxa de inadimplência em algum período causará uma elevação na taxa de risco bancário para o próximo período. As firmas, portanto, não sofrem restrição de crédito, mas de preço do crédito monetário. Também há mecanismos de interação local nas decisões de preços das firmas com os maiores estoques de débitos acumulados que realizam uma pesquisa de preço junto aos concorrentes no sentido de reduzir (ou aumentar) o seu mark up em dez por cento se o seu preço for maior (ou menor) do que a média de preços de seus concorrentes, e nas decisões de consumidores que fazem uma pesquisa de preço junto às firmas. Por sua vez, os mecanismos de inferência intertemporal local estão presentes nas decisões de produção de firmas e de fixação da taxa de juros pelo banco monopolista. Do lado das firmas, para estimar a demanda esperada para um dado período, as firmas seguirão um conjunto de 10 regras simples e adaptativas que diferem uma da outra de acordo com a demanda efetiva passada (que varia de 1 a 3 períodos) e se elas são mais otimistas ou pessimistas ;enquanto que do lado financeiro o banco monopolista fixa o mark up bancário com base na taxa de default do período anterior. Por último, a origem da instabilidade financeira consiste nas interações diretas e indiretas entre as firmas, consumidores e o banco monopolista e da combinação de três parâmetros 
de controle: a.) um choque de demanda agregada que assume os valores 5000, 10000 e 20000 , b.) uma medida da transparência de preços para os consumidores captada pela quantidade de telefonemas que os consumidores fazem para quotar os preços, e c.) uma medida da rigidez do mark up mensurada pela quantidade de firmas que fazem telefonemas para quotar preços de seus concorrentes no sentido de alterar o seu mark up. Uma propriedade interessante é que as interações complexas entre os agentes heterogêneos (firmas, consumidores e o banco monopolista) na presença de uma combinação de elevado grau de flexibilidade do mark up e de transparência de preço aos consumidores, é capaz de transformar um sistema robusto financeiramente em um sistema com alto grau de fragilidade financeira com crescente e persistente presença de firmas espulativas e/ou ponzi.

Apesar dos avanços teóricos, o modelo de Lima e Freitas (2007b) possui como principais limitações teóricas as suposições de produtividade do trabalho constante e distribuída de forma homogênea entre as firmas, e de taxa de salário nominal constante, inviabilizando-se a integração teórica entre o crescimento, o ciclo econômico, a inovação e as finanças.

No presente trabalho, supõe-se que as firmas, movidas pela concorrência schumpeteriana, via inovação, buscam financiar suas atividades no sistema bancário. Dependendo da taxa de sucesso em inovar, as firmas que apresentarem baixa performance na forma de lucros de monopólio por inovar, poderão evoluir de um esquema de financiamento sustentado ou hedge, para posições especulativas e até mesmo Ponzi, no sentido dado por Minsky (1982). A instabilidade ou a fragilidade financeira emerge como uma propriedade complexa da interação de firmas produtivas entre si e com o sistema bancário produzindo ciclos e afetando o crescimento econômico. A análise envolve comportamento evolucionário por parte das firmas, no sentido de que uma firma fixa o preço e escolhe o nível de produção e a melhor estratégia de inovação ${ }^{5}$ em cada momento do tempo observando o comportamento das demais firmas. Na outra ponta os bancos fixam o spread com base na sua percepção de risco de crédito.

$\mathrm{O}$ artigo contribui à literatura econômica do ciclo e do crescimento $^{6}$ ao mostrar que é possível realizar a construção de uma teoria integrada do ciclo e crescimento, da inovação e do sistema bancário desde que se recorra a uma abordagem baseada em agentes heterogêneos. Mostra-se que o ciclo econômico não é um atributo exclusivo do comportamento do agente (firma) individual, nem é uma

(5) A inovação tem o significado de aumento de produtividade, o qual pode ocorrer por três canais distintos: via learningbydoing puxado pela demanda, por imitação e por inovação ou descoberta interna de novos processos.

(6) Estamos nos referindo a ambas dinâmicas ciclo e crescimento devido ao fato de que o modelo apresentado na seção 1 gera simultaneamente processos cíclicos na forma de instabilidade financeira, ao longo de uma trajetória de crescimento impulsionada pela inovação tecnológica. $\mathrm{O}$ fato do modelo supor um crescimento exógeno da demanda agregada, que poderia descaracterizar a dinâmica do crescimento, de fato não desconfigura o modelo, pois mesmo diante de um crescimento igual a zero da demanda, a inovação tecnológica endógena na forma de aumento de produtividade mantém o processo de crescimento no longo prazo, sujeito a ciclos de curta duração. 
restrição ou uma propriedade pré-existente do nível macroeconômico, mas sim da interação constante entre todas as partes do sistema.

O restante do artigo é organizado como segue. A seção 1 descreve a estrutura do modelo macroeconômico baseado em agentes heterogêneos e evolucionários. A seção 2 analisa os resultados das simulações do modelo em dois regimes de inovação. A conclusão do artigo é apresentada na última seção.

\section{Estrutura do modelo}

O modelo apresentado a seguir assemelha-se em muito ao modelo de Lima e Freitas (2007b) mas remove algumas de suas limitações. A taxa de progresso técnico representada pela produtividade do trabalho e a taxa de salário nominal e real, passam ,a ser endógenas e influenciada por mecanismos de feedback. Esta simples mudança produz efeitos importantes na dinâmica da economia e é o que permite avançar na formulação de uma teoria integrada do crescimento e do ciclo econômico com a mudança tecnológica e o financiamento bancário. A endogenização da mudança tecnológica, e da dinâmica de salários nominais e reais, permitirá analisar comparativamente a dinâmica evolucionária de diferentes regimes tecnológicos, como mostraremos na seção 2.

Neste esquema complexo ${ }^{7}$, a fragilidade financeira da economia no sentido dado por Minsky (1982), populada com firmas sujeitas a comportamentos adaptativos que podem assumir formas hedges, especulativas e Ponzi, é uma propriedade emergente gerada pelo comportamento interativo de firmas em competição tecnológica e adaptativo do setor bancário.

Em linha com esta abordagem evolucionária, este artigo adiciona algumas contribuições teóricas a literatura evolucionária formalizando, com o uso de um modelo baseado em agentes, as relações entre o regime de financiamento (no sentido de Minsky), a mudança tecnológica, o ciclo e crescimento econômico. Mais especificamente, o modelo assume as propriedades emergentes já exploradas por Lima e Freitas (2007b), porém avança teoricamente relacionando-as com a dinâmica tecnológica e a variação do produto de uma economia.

O modelo apresentado a seguir formaliza uma economia habitada por firmas heterogêneas e por um sistema bancário adaptativo. Mais especificamente isto significa que as firmas podem diferenciar-se quanto ao preço praticado, a parcela de mercado, ao volume de recursos destinado à $\mathrm{P} \& \mathrm{D}$, à formação de expectativas de vendas, à necessidade de financiamento, e ao nível tecnológico mensurada pela produtividade do trabalho. O caráter adaptativo do sistema bancário implica que o volume de crédito pode sofrer restrições via preço (mark up) na medida que os

(7) Tal como definida por Waldrop (1992); Gribbin (2005) e Érdi (2008). 
bancos perceberem que o grau de endividamento das firmas aumentou. O financiamento das firmas tem efeitos simultâneos contrários na dinâmica econômica e na conformação dos ciclos. Por um lado, o aumento do financiamento pode aumentar a taxa de sucesso da inovação e, portanto, os lucros da firma. Porém, o aumento do endividamento pode mudar o regime de financiamento da empresa de hedge para especulativo ou Ponzi, forçando uma reação do sistema bancário que restringe o crédito aumentando o spread. O regime de financiamento pode então ter efeitos macroeconômicos adversos a depender da estratégia de financiamento das firmas e da propensão ou capacidade tecnológica da economia ou das firmas. $\mathrm{O}$ modelo oferece, portanto, uma base teórica à análise das relação complexas entre os regimes tecnológicos e os regimes de financiamento e os respectivos efeitos macroeconômicos que emergem deste comportamento dos agentes.

\subsection{Produção, demanda e estoque}

Do lado da produção supõe-se uma economia puramente baseada em trabalho, onde as oscilações do produto podem ser determinadas pela variação da quantidade de trabalho empregada a cada período de tempo. Desta forma pode-se assumir uma função de produção com coeficientes fixos, $Y=\min \{K / b ; L / a\}$, conformeLeontief e Strout (1963). A produção da firma depende então da quantidade de trabalho mobilizada e do coeficiente técnico de produção $\left(a_{i, t}\right)$, o qual varia no tempo e entre as firmas dependendo do aprendizado tecnológico desenvolvido em cada firma. Portanto, uma firma $i$, produzirá $X_{i, t}$ unidades de produto no período de tempo $t$, contratando uma quantidade $L_{i, t}$ de trabalho com uma produtividade $A_{i, t}=1 / a_{i, t}$, a qual aumentará com as inovações introduzidas pela firma, conforme descrito mais adiante na subseção 1.3:

$$
X_{i, t}=\frac{L_{i, t}}{a_{i, t}}
$$

Para executar seu plano de produção, uma firma contrata trabalho em um dado período de tempo $t$ conforme a demanda esperada $\left(X_{i, t}^{E x p}\right)$ para o período deduzida do saldo de estoque não planejado $\left(X_{i, t-1}^{S}\right)$ existente no final do período anterior:

$$
L_{i, t}=a_{i, t}\left(X_{i, t}^{\operatorname{Exp}}-X_{i, t-1}^{S}\right)
$$

Tendo em vista que o objetivo principal do modelo é analisar as interações entre as estratégias de financiamento e de inovação das firmas e os efeitos macroeconômicos nos ciclos econômicos, o lado da demanda da economia é tratado como exógeno, porém variável. A demanda é determinada primeiramente em termos 
agregado $\left(X_{i, t}^{A g}\right.$ ) e em seguida é distribuída entre as firmas de acordo com seus respectivos market share $\left(m s_{i, t}\right)$, os quais variam em função dos preços praticados a cada momento do tempo. Como as firmas calculam a produção com base em uma expectativa de vendas ( $X_{i, t}^{E x p}$ ) conforme definida na equação 6 , a produção e a demanda efetiva ao nível da firma poderão divergir em um determinado período causando a formação de estoques ou o excesso de demanda. Esta diferença afetará o lucro da empresa no período e pode até mesmo causar prejuízo, forçando a empresa a financiar seu fluxo de caixa no sistema bancário caso não tenha lucros acumulados suficientes. A demanda agregada varia de acordo com a equação (3), onde $g$ é uma taxa de crescimento exógena e constante e $\eta$ é um choque aleatório normalmente distribuído em torno de um valor médio igual e zero com variância constante.

$$
X_{t}^{A g}=(1+g+\eta) X_{t-1}^{A g} \quad \text { onde } \quad \eta \text { i.i.d. } N\left(0, \sigma_{1}^{2}\right)
$$

Esta demanda agregada é distribuída entre as firmas e define sua demanda efetiva ( $X_{i, t}^{E}$ ). A distribuição da demanda (market share) depende da competitividade individual da firma $\left(E_{i, t-1}\right)$ ser maior ou menor do que a competitividade média $\left(\bar{E}_{t-1}\right)$, a qual por sua vez é definida na equação (7), mais adiante. A competitividade individual é igual ao inverso do preço $\left(E_{i, t}=1 / P_{i, t}\right)$, ao passo que a competitividade média é igual a média ponderada da competitividade individual, cujo fator de ponderação é o market share individual (Dosi; Freeman; Fabiani, 1994). Assim, temos:

$$
X_{i, t}^{E}=m s_{i, t} X_{t}^{A g}
$$

Como as firmas, baseadas em suas expectativas, produzem uma quantidade $X_{i, t}$, e como sua demanda efetiva é dada por $X_{i, t}^{E}$, no caso em que a produção é maior que a demanda individual a diferença não comercializada será acumulada na forma de estoque. Nos casos em que a demanda efetiva é maior que a produção mais os saldos remanescentes de produto, as empresas não acumulam pedidos e o saldo em estoque será zero.

$$
X_{i, t}^{S}=\left\{\begin{array}{cc}
X_{i, t}+X_{i, t-1}^{S}-X_{i, t}^{E} & \text { se } \mathrm{X}_{\mathrm{i}, \mathrm{t}}^{\mathrm{E}}<\mathrm{X}_{\mathrm{i}, \mathrm{t}}+\mathrm{X}_{\mathrm{i}, \mathrm{t}-1}^{\mathrm{S}}, \\
0 & \text { se outro modo }
\end{array}\right.
$$

No modelo supõe-se que as firmas hedge, financeiramente robustas, são otimistas e projetam suas vendas considerando-se a maior taxa de crescimento das suas vendas já realizadas nos últimos três períodos, enquanto que as firmas excessivamente endividadas, mais adiante chamadas de firmas ponzi, são pessimistas e projetam suas vendas usando a menor taxa de crescimento já realizadas 
nos últimos três períodos. Por último, supõe-se que as firmas medianamente endividadas, mais adiante chamadas de firmas especulativas, projetam suas vendas com base nas vendas realizadas no período anterior.

$$
\begin{array}{ll}
X_{i, t}^{E x p, H} & =X_{i, t-1}^{E}\left(1+\max \left(\hat{X}_{i, t-1}^{E}, \hat{X}_{i, t-2}^{E}, \hat{X}_{i, t-3}^{E}\right)\right) \\
X_{i, t}^{E x p, E} & =X_{i, t-1}^{E} \\
X_{i, t}^{E x p, P} & =X_{i, t-1}^{E}\left(1+\min \left(\hat{X}_{i, t-1}^{E}, \hat{X}_{i, t-2}^{E}, \hat{X}_{i, t-3}^{E}\right)\right)
\end{array}
$$

em que $\hat{X}$ significa a taxa de variação em termos percentuais, isto é, $\dot{X} / X$. Este mecanismo de correção das expectativas faz com que eventuais diferenças entre a produção da firma e a demanda efetiva sejam corrigidas no tempo. Nos casos em que a demanda efetiva for maior do que a produção, as firmas não atendem a produção imediatamente mas corrigem a produção nos períodos seguintes, uma vez a demanda esperada conforme equação 6 interage com a produção da firma em (2) e depois (1) . Se a demanda efetiva aumentar em $t$, a produção irá aumentar em $t+1$, e nos casos em que $X_{i, t}^{E}>X_{i, t}$ esta diferença é eliminada nos períodos seguintes. Este mecanismo permite que o ajustamento no mercado de bens, ou o equilíbrio entre oferta e demanda, não seja instantâneo, o que pressuporia um mecanismo informacional ou de coordenação perfeita entre consumidores e firmas que não existe na prática. Nesta versão do modelo podem ocorrer situações em que algumas firmas tenham estoque maior que zero enquanto outras firmas tenham excesso de demanda. No entanto as firmas corrigem suas posições de um período para outro, embora não o façam todas no mesmo instante de tempo. Ao longo de poucos períodos, em função da defasagem de tempo da equação (6) a oferta e demanda ao nível da firma oscila em torno de uma trajetória de equilíbrio sem acumular grandes diferenças.

\subsection{Preço, mark-up, receita e lucro da firma}

A venda efetiva da firma dependerá de sua estratégia de fixação de preços e, portanto, da fixação de mark-up. A fim de aumentar as vendas as firmas competem no mercado consumidor repassando aos preços os ganhos de produtividade obtidos pelo seu esforço em inovar. O mark-up da empresa deve ser suficiente para cobrir os custos operacionais (basicamente salários), gastos em pesquisa e desenvolvimento de tecnologias e despesas financeiras. Se, por um lado, as firmas podem recorrer a financiamento para aumentar sua pesquisa e produtividade, tornando-se assim mais competitivas uma vez que a produtividade é repassada aos preços, por outro elas incorrem em despesas financeiras que encarecem o produto, estabelecendo-se aqui uma conexão importante entre inovação e sistema bancário que está longe de ser uma relação linear. Na seção 2, quando for realizada a apresentação dos resultados das simulações computacionais do modelo, voltaremos a este ponto com mais detalhes. No caso de uma firma individual não manter dívida acumulada e não demandar 
qualquer crédito no período corrente, assume-se que seguirá um procedimento de cobrar no período corrente o mesmo preço que cobrava no período prévio. A formação de preços da firma é dada pela equação (7):

$$
P_{i, t}=\left\{\begin{array}{cc}
\left(1+z_{i, t}\right) \frac{W_{i, t}}{X_{i, t}^{E x p}} & \mathrm{se} \mathrm{DF}_{\mathrm{i}, \mathrm{t}}^{\mathrm{s}}=0, \\
\left(1+z_{i, t}\right) \frac{\left(1+i_{i, t}\right)\left(D_{i, t}+D_{i, t-1}^{S}\right)}{X_{i, t}^{E x p}} & \text { outro modo }
\end{array}\right.
$$

em que $z_{i, t}>0$ é a taxa de mark-up das firmas, $D_{i, t}$ o montante de dívida nova contraída no período $t, D_{i, t-1}^{S}$, o estoque acumulado de dívida da firma no período $t-1, D F_{i, t}^{S}$ é a dívida total no período $t, i_{t}$ é a taxa de juros incluído o mark-up bancário e $X_{i, t}^{\operatorname{Exp}}$ a sua expectativa de vendas. Deve-se atentar ao fato de que o cálculo do preço como especificado na primeira condição da equação (7) não significa que a única fonte de mudança de preço seja a razão entre a dívida total da empresa e a expectativa de vendas. De fato, quando a empresa consegue inovar, diminuindo $\left(a_{i, t}\right)$, dado um salário nominal $\left(V_{i, t}\right)$, reduz o valor dos custos salariais [conforme equação (9)], aumenta os lucros, diminui sua dívida $\left(D F_{i, t}^{S}\right)$ e, com isso, pode diminuir o seu preço. Há, portanto, um canal, não muito óbvio a princípio, pelo qual o progresso tecnológico afeta o preço da firma. A produtividade tem efeitos positivos sobre o salário, sobre o lucro e sobre o regime de endividamento da firma. Isto terá consequências importantes na análise dos resultados simulados.

A taxa de mark-up, por sua vez, é fixada por um comportamento adaptativo e interativo pelas firmas. Um dos comportamentos que caracteriza este modelo como evolucionário é o fato das firmas ajustarem seus mark-ups de maneira adaptativa com base na observação do comportamento das demais firmas.

A suposição é de que as firmas especulativas e ponzi realizam uma pesquisa de preços junto a quatro empresas ${ }^{8}$ selecionadas aleatoriamente e computam o preço médio. No caso do preço ser maior do que o preço médio $\left(\bar{P}_{t}\right)$, a firma reduzirá seu mark-up para o próximo período para $(1-\rho)$ do praticado no período corrente, enquanto que no caso do seu preço ser menor, aumentará o mark-up em $(1+\rho)$, em que $\rho>0$. Esta interação entre as firmas na fixação de preços, um mecanismo de interação local ausente nos modelos com firmas representativas, permite a firma ajustar seu mark-up às condições do mercado como um todo. Ela nem aumentará nem diminuirá demais o seu preço, de forma a se isolar em uma posição

(8) O número exato de firmas não é crucial para determinar os resultados, mas pode-se admitir qualquer número ou até mesmo a comparação do preço da firma com o preço médio de mercado. É uma questão de capacidade de monitoramento do mercado por parte da firma. 
mercadológica extrema. Embora a firma procure se diferenciar em preço no mercado, ela está sempre monitorando os concorrentes para evitar quedas excessivas de preço no caso de uma inovação drástica que produza um grande aumento de produtividade. Formalmente, temos:

$$
z_{i, t}= \begin{cases}(1-\rho) z_{i, t-1} & \text { se } \mathrm{P}_{\mathrm{i}, \mathrm{t}}>\overline{\mathrm{P}}_{\mathrm{t}}, \\ (1+\rho) z_{i, t-1} & \text { se } \mathrm{P}_{\mathrm{i}, \mathrm{t}}<\overline{\mathrm{P}}_{\mathrm{t}}\end{cases}
$$

Uma vez que a firma definiu sua taxa de markup e consequentemente seu preço, estas variáveis irão determinar a cada período de tempo o seu market share ( $\left.m s_{i, t}\right)$, isto é, a parcela da demanda agregada $\left(X_{i, t}^{A g}\right)$ que lhe cabe. A conquista de market share depende da competitividade da firma no mercado, a qual está relacionada ao preço. Se a competitividade for definida como sendo o inverso do preço da firma, como segue:

$$
E_{i, t}=\frac{1}{P_{i, t}}
$$

pode-se calcular o market share supondo que uma firma terá uma parcela maior do mercado caso seu preço esteja abaixo do preço médio do mercado, e terá um market share menor se o preço estiver acima da média, conforme a equação (7):

$$
m s_{i, t}=\left[1+\beta\left(\frac{E_{i, t-1}}{\bar{E}_{t-1}}-1\right)\right] m s_{i, t-1} \quad e \quad 0<\beta<1
$$

onde $\beta$ é um parâmetro comum às firmas que mede a sensibilidade do market share em relação ao grau de competitividade (preço). Quanto maior $\beta$, mais uma firma ganha mercado se seu preço estiver abaixo da média, e vice-versa.

Tendo definido seu preço e seu market share, a firma estará em condições de calcular sua receita e os custos operacionais e, ao fim, seu lucro. A receita total da firma é composta de receita operacional e da receita financeira obtida pelos juros recebidos sobre os lucros acumulados remunerados pela taxa de juros bancária: supõe-se que as firmas para evitar custos de oportunidade do capital apliquem o seus lucros retidos no sistema bancário. Por seu turno, os custos totais são compostos de custo operacional(neste modelo exclusivamente salários), gastos em pesquisa e desenvolvimento como proporção do lucro acumulado no início do período $t$ e, por fim, despesas financeiras sobre a dívida acumulada. Assim, o lucro total da firma no final do período de tempo $t$ será:

$$
\Pi_{i, t}=\left(R_{i, t}^{O}+R_{i, t}^{F}-W_{i, t}-i_{t} D F_{i, t-1}^{S}-P \& D\right)
$$


Na equação do lucro (8), $P \& D=\varphi_{i} \Pi_{i, t-1}$, em que $\left(\varphi_{i}\right)$ é um parâmetro que capta o percentual do lucro acumulado destinado para $P \& D$ a cada período de tempo, o qual é constante entre os períodos e assume valor igual para todas as firmas. $R_{i, t}^{O}$ é a receita operacional da firma, $R_{i, t}^{F}$ é a receita financeira da aplicação de lucros acumulados no início do período t, já descontado os custos salariais e os gastos em $\mathrm{P} \& \mathrm{D}, W_{i, t}$ é o valor total dos salários pagos ou os custos variáveis totais, e $i^{*}$ é uma taxa nominal de juros que os bancos cobram das operações de empréstimos. Uma das restrições desta versão do modelo é o fato de $\varphi_{i}$ ser constante no tempo, significando que uma firma mantém sempre a mesma estratégia e a usa na mesma intensidade qualquer que seja o cenário econômico do momento. $\mathrm{O}$ custo total de mão de obra de uma firma $\left(W_{i, t}\right)$ é realmente o único custo de produção envolvido e depende do valor do salário nominal $\left(V_{t}\right)$, do inverso da produtividade do trabalho $\left(a_{i, t}=1 / A_{i, t}\right)$ e do volume de produção $\left(X_{i, t}\right)$ :

$$
W_{i, t}=V_{t} a_{i, t} X_{i, t}
$$

O salário nominal unitário $\left(V_{i, t}\right)$, por sua vez, é corrigido pela taxa de inflação $\left(\hat{P}_{t-1}\right)$ e pela taxa de variação da produtividade do trabalho $\left(\hat{A}_{t-1}\right)$ em $t-1$ , sendo que $\theta$ é uma variável aleatória com distribuição uniforme que varia de 0,95 a 1,05 , podendo assumir outros intervalos em diferentes simulações.

$$
V_{t}=\left[1+\theta\left(\hat{P}_{t-1}+\hat{A}_{t-1}\right)\right] V_{t-1}
$$

\subsection{Inovação e produtividade}

Uma vez que a mudança tecnológica é levada em conta, aperfeiçoamentos tecnológicos que elevam a produtividade do trabalho afetarão a lucratividade e a fragilidade financeira por afetar os custos unitários de trabalho e, assim, a competitividade. Com efeito, esta influência torna-se mais intensa e complexa quando a inovação tecnológica é endógena. O processo de inovação, neste modelo, pode ocorrer de três fontes distintas: por um processo cumulativo do tipo learning by doing(Arrow, 1962), por imitação e por inovação (Nelson e Phelps, 1966; Nelson e Winter, 1982).

O uso simultâneo de três formas distintas de inovação intensifica o processo de concorrência schumpeteriana e permite que as firmas, mesmos não conseguindo inovar de forma mais radical, possam imitar mesmo que imperfeitamente ou ainda acumular conhecimento sobre seu próprio processo produtivo. Este processo concorrencial deveria tornar o sistema econômico mais robusto e resistente a crises cíclicas na medida que as firmas possuem maneiras de se adaptar tecnologicamente, 
mesmo quando não são as pioneiras na inovação. A consideração distinta e simultânea dos diferentes processos de inovação tem sido reconhecido como importante pela literatura (Segestrom, 1991; Geisendorf, 2009).

O primeiro canal de mudança, learning-by-doing, ocorre quando a produtividade aumenta em função do próprio aumento da produção. Este processo de crescimento da produtividade tem sido chamado na literatura de "Lei de KaldorVerdoorn", devido aos trabalhos de Verdoorn (1949) e Kaldor (1961), e posteriormente generalizada algebricamente por Arrow (1992).Esta ideia é representada na equação (11), onde a taxa de aprendizado tecnológico depende linearmente da taxa de crescimento da produção:

$$
\hat{A}_{i, t}^{L D}=\delta_{1} \hat{X}_{i, t-1} \quad \text { se } \quad \hat{X}_{i, t-1}>0
$$

$\mathrm{e}$

$$
A_{i, t}^{L D}=\left(1+\hat{A}_{i, t}^{L D}\right) A_{i, t-1}
$$

onde $\delta_{1}$ é coeficiente de Kaldor-Verdoorn ${ }^{9}, \hat{A}_{i, t}^{L D}$ é a taxa de aprendizado tecnológico na produção e $\hat{X}_{i, t}$ é a taxa de crescimento da produção entre os períodos $t-2$ e $t-1$, e $A_{i, t-1}$ é a produtividade da firma em $t-1$. O parâmetro $\delta_{1}$ representa a sensibilidade da taxa de crescimento da produtividade do trabalho às variações relativas na produção, o qual é exógeno e comum a todas firmas. A restrição $\hat{X}_{i, t}>0$ imposta na equação (11) implica que eventuais variações negativas na produção não se transformem em desaprendizado tecnológico.

A segunda fonte de mudança de produtividade do trabalho é a imitação, a qual é realizada por todas as firmas, incluindo as financeiramente frágeis. Este tipo de inovação é estocástico e local. Supõe-se que a tecnologia a ser imitada possui componentes locais, tácitos e específicos, e que a capacidade de imitação da firma é limitada e, destarte, apenas uma proporção da diferença entre a produtividade da firma imitada é que poderá significar aumento de produtividade da imitante. $\mathrm{Na}$ equação (13), a tecnologia de produção obtida por imitação é o resultado da pesquisa aleatória em três firmas concorrentes:

$$
A_{i, t}^{I M, \text { max }}=\max \left(A_{1, t-1}^{I M}, A_{2, t-1}^{I M}, A_{3, t-1}^{I M}\right)
$$

(9) A chamada 'Lei' de Kaldor-Verdoorn na verdade, é uma dependência positiva da taxa de crescimento da produtividade do trabalho em relação à taxa de crescimento do produto, a qual, por sua vez, é determinada pela demanda agregada. Embora a equação (11) aplica esta correlação no plano microeconômico, a relação agregada é preservada. 
Uma vez escolhida a firma a ser imitada, o passo seguinte é definir quanto de produtividade poderá ser copiada, e isto depende da distância tecnológica entre as firmas imitante e imitada conforme a equação a seguir:

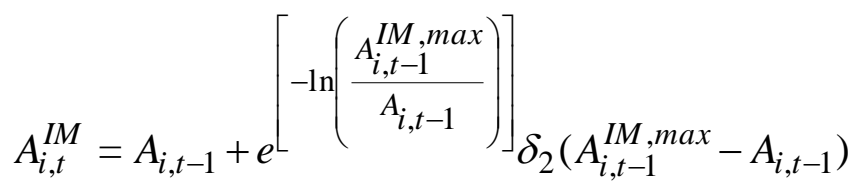

A forma funcional da equação (14) captura o efeito da distância tecnológica. Uma firma que consegue imitar pode não fazê-lo de forma perfeita e terá maiores dificuldades em dar um "salto" tecnológico, mesmo que na forma de imitação, quanto mais distante a sua produtividade estiver em relação à firma imitada. $\mathrm{O}$ expoente do termo neperiano captura o efeito distância o qual segue um processo exponencial inverso. O parâmetro $\delta_{2}$ regula a quantidade máxima da diferença de produtividade entre a firma copiada e a própria firma que será absorvida.

A terceira fonte de mudança tecnológica poupadora de mão-de-obra é a inovação realizada somente por firmas financeiramente robustas ${ }^{10}$. No início de cada período de tempo, as firmas tomam a decisão de inovar usando uma fração da diferença entre os lucros acumulados no período anterior e o total de salários pagos.

Embora a inovação tecnológica dependa de gastos em P\&D, trata-se de um processo estocástico em dois estágios. No primeiro estágio ocorre o evento sucesso ou falha na descoberta de uma inovação, enquanto que no segundo estágio ocorre o evento aumento de produtividade do trabalho que segue uma função exponencial inversa como em Nelson e Winter (1982)e Valente e Andersen (2002).

$\mathrm{Na}$ equação (15), a probabilidade de inovação segue um processo exponencial inverso e depende dos gastos em P\&D e da produtividade do trabalho acumulada na firma, a qual representa o efeito da cumulatividade da mudança tecnológica: as firmas que obtiveram sucesso no processo de inovação no passado, terão maiores probabilidades para inovar no presente. Por sua vez, na equação (16), para captar o crescimento não linear da produtividade do trabalho, supõe-se que o resultado do sucesso em inovar é extraído de uma distribuição exponencial inversa com média $\ln \left(A_{i, t}\right)$ e variância $\sigma_{2}^{2}$. Este resultado só e implementado se o valor da probabilidade em inovar $\left(P_{i, t}^{I N}\right)$ calculada em (15) for maior ou igual um número pseudoaleatório gerado por um função de distribuição de probabilidade uniforme que varia entre 0 e 1 :

$$
P_{i, t}^{I N}=1-e^{\left[-\gamma_{1}\left(\varphi_{i} \Pi_{i, t}^{S}\right)-\gamma_{2} A_{i, t-1}^{I N}\right]}
$$

(10) São as firmas hedge com lucros acumulados que cobrem os custos salariais e os gastos em P\&D. 
onde $\gamma_{1}$ e $\gamma_{2}$ são os parâmetros que possibilitam ajustar a sensibilidade da probabilidade de inovar em relação aos gastos em $\mathrm{P} \& \mathrm{D}$ e à produtividade do trabalho acumulada ou nível tecnológico da firma $\left(A_{i, t-1}^{I N}\right)$, respectivamente. A produtividade do trabalho acumulada na firma é dada por:

$$
A_{i, t}^{I N}=\left\{\begin{array}{ccl}
e^{N o r m}\left(\ln A_{i, t-1}, \sigma_{2}^{2}\right) & \text { se } & P_{i, t}^{I N} \geq R N D(0,1) \\
A_{i, t-1} & \text { se } & P_{i, t}^{I N}<R N D(0,1)
\end{array}\right.
$$

Embora com menor intensidade, no processo de inovação supõe-se também a presença de componentes locais, tácitos e específicos, e cumulativos do aprendizado tecnológico, na medida em que depende dos próprio valor defasado da produtividade. Como ocorrem em processos evolucionários, a mudança ocorre sempre localmente e marginalmente, sendo os efeitos macroeconômicos apenas percebidos no longo prazo. Outra suposição é que o processo de inovação é altamente incerto. A firma pode descobrir uma inovação de processo com produtividade maior ou menor do trabalho do que a do processo de produção em uso. Se for menor, obviamente, não será implementado pela escolha que ocorrerá na equação (17). A equação (17) mostra que o processo de produção escolhido será aquele que proporcionar a maior produtividade do trabalho, seja por learning by doing, inovação ou imitação:

$$
A_{i, t}=\max \left(A_{i, t-1}^{L D}, A_{i, t-1}^{I M}, A_{i, t-1}^{I N}\right)
$$

\subsection{Financiamento da firma e setor bancário}

A fim de analisar a evolução e os efeitos de mudanças no regime de financiamento da firma sobre o ciclo econômico, as atividades da firma nesta economia vão além das atividades produtivas e pesquisa e também envolvem relações com o sistema bancário. As firmas com prejuízos no período fazem operações de empréstimos para financiar todo seu fluxo de caixa deficitário. As operações são contratadas por apenas um período e caso a firma não obtenha lucros suficientes para cobrir o pagamento de juros e/ou amortização do principal, uma nova operação de crédito é contratada no período seguinte até que a firma consiga eliminar sua dívida.

O conjunto das equações (18) a (24) formaliza a demanda de crédito, o financiamento das firmas pelo setor bancário e a fixação da taxa de juros para aplicação de recursos por parte do sistema bancário. O sistema bancário é simplificado ao máximo e pode ser entendido como constituindo um pool de firmas bancárias representativas ou uma única firma bancária que recebe depósitos remunerados e concede créditos às firmas produtivas. Outra simplificação é que não há uma distinção entre uma taxa de juros de captação e de aplicação. Este 
procedimento significa assumir uma oferta de moeda endógena na linha de Kaldor (1982; 1985) e Moore (1988), também conhecida como abordagem "horizontalista". Segundo esta abordagem, os bancos são passivos e acomodam a quantidade de moeda cuja elasticidade de oferta é infinita a uma dada taxa de juro. A restrição de crédito, portanto, se faz por meio do preço do crédito, e não pelo lado da quantidade.

Segue-se que $D_{i, t}$ representa a demanda por crédito pela firma para financiar aquela porção de seu fluxo de produção que não pode ser coberto pelos lucros acumulados $\left(\Pi_{i, t}\right)$. Logo, a oferta de crédito em qualquer período é por sua vez endógena, determinado pela demanda de fundos à taxa de juros corrente:

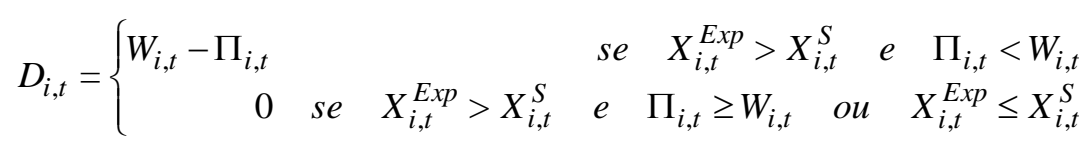

A taxa de juros cobrada pelas operações de empréstimos é calculada aplicando uma taxa de mark up bancária $\left(h_{t}\right)$ sobre a taxa básica de juros que, por sua vez, é constante e determinada exogenamente pela autoridade monetária.

$$
i_{t}=\left(1+h_{t}\right) i^{*}
$$

Os bancos formulam sua política de fixação da taxa de juros de empréstimo $\left(i_{t}\right)$ com base na avaliação do nível de inadimplência agregado da economia e uma vez fixada esta taxa, esta passa a ser utilizada para todas as firmas, independentemente de sua situação financeira. $O$ mecanismo simplifica o entendimento da relação entre os regimes de financiamento (hedge, especulativo ou ponzi) com a inovação e o ciclo econômico. O mark up bancário $\left(h_{t}\right)$ ajustado pelo risco poderá mudar a cada período de acordo com um indicador de empréstimos não pagos $\left(d_{t}\right)$, o qual é calculado como sendo a razão entre as dívidas não pagas em um período em relação ao total de dívidas existentes:

$$
d_{t}=\frac{\left(D_{t}^{T}-D_{t}^{P}\right)}{D_{t}^{T}}
$$

onde $D_{t}^{T}$ é o total de dívidas do sistema financeiro, apurado pela soma das dívidas das firmas, e $D_{t}^{P}$ é o total de dívidas não pagas. Portanto o mark-up bancário ajustado pelo risco é dado por:

$$
h_{t}=h^{\min }+\alpha d_{t-1}, \quad 0<\alpha<1
$$

onde $h^{\text {min }}$ é o mark up mínimo praticado pelos bancos e $\alpha$ é um parâmetro que mede a sensibilidade do mark-up ao grau de risco com que o sistema bancário está operando a cada momento. Assume-se que $h^{\text {min }}$ é fixado exogenamente. 
Com efeito, um aumento na taxa de default em algum período conduzirá a um aumento na taxa esperada de default para o próximo período e, então, a um aumento no mark-up bancário ajustado pelo risco para o próximo período. As evidências empíricas para este comportamento do mark up podem ser encontradas em Saunders e Schumacher (2000), Angbazo (1997) e Brock e Rojas-Suarez (2000).

De acordo com a caracterização de Minsky (1982), unidades de financiamento hedge são aquelas que possuem fluxo de caixa suficiente para pagar os juros da dívida e amortizar parcela do principal acordada, enquanto as unidades especulativas são aquelas que podem cumprir compromissos de pagamentos de juros mas não a amortização. Por fim, as unidades Ponzi são as firmas que não conseguem pagar todos os juros contratados e precisam refinanciar a dívida e os juros não pagos. Esta classificação de regimes de financiamento pode ser formalizada através das expressões a seguir:

$$
\begin{gathered}
\text { Hedge }=R_{i, t}^{F} \geq\left(1+i_{t}\right)\left(D_{i, t-1}^{S}+D_{i, t}\right) \\
\text { Especulativa }=\left(D_{i, t-1}^{S}+D_{i, t}\right) \leq R_{i, t}^{F}<\left(1+i_{t}\right)\left(D_{i, t-1}^{S}+D_{i, t}\right) \\
\text { Ponzi }=R_{i, t}^{F}<\left(D_{i, t-1}^{S}+D_{i, t}\right)
\end{gathered}
$$

Enquanto identificar a postura financeira de cada firma proporciona uma medida de sua fragilidade financeira, classificar todas as firmas em uma economia conforme estas categorias proporciona uma forma analítica útil de avaliar o nível de fragilidade financeira sistêmica em qualquer período de tempo. De fato, quanto maior a proporção de firmas especulativas e Ponzi, maior o grau de fragilidade financeira da economia. Para Minsky (1982), as estruturas financeiras capitalistas tem uma tendência inerente a mover-se de um estado de robustez para outro de fragilidade financeira ao longo do tempo.

O modelo baseado em agentes explicado acima, embora tenha uma estrutura geral relativamente simples, com várias firmas produtivas e um pool de firmas bancárias, como observado contém elementos suficientes para gerar dinâmicas macroeconômicas emergentes a partir de comportamentos adaptativos e de interações complexas entre agentes heterogêneos. Na seção seguinte apresenta-se os resultados das simulações de alguns cenários para diferentes regimes tecnológicos (alto e baixo) e regimes de financiamento, onde firmas são mais ou menos propensas a recorrer ao sistema bancário. Tais configurações produzem diferentes resultados macroeconômicos em termos de ciclo e crescimento macroeconômico.

\section{Resultados de simulações}

A presença de agentes heterogêneos e de mecanismos de feedbacks positivos e negativos, no modelo complexo de crescimento e ciclo econômico, torna 
inviável uma solução formal analítica pelo uso de técnicas de otimização dinâmica. Assim, as propriedades emergentes quanto as conexões entre os regimes de inovação, os regimes de financiamento, o crescimento e o ciclo econômico, foram exploradas por meio de técnicas de simulação computacional com o uso do software Laboratory for Simulation and Development, versão 6.4, criado por Valente (2008).

Para avaliar a dinâmica de diferentes regimes de inovação sujeitos a endividamento endógeno, foram realizadas simulações com dois cenários. O cenário 1 é caracterizado como sendo uma economia de baixo desenvolvimento tecnológico e o cenário 2 de alto. O que distingue basicamente uma economia da outra em termos de desenvolvimento tecnológico são os parâmetros $\gamma_{1}$ e $\gamma_{2}$ da equação (15), os quais aumentam a probabilidade de ocorrência de inovação em um período de tempo, quanto maior o valor que assumem. Parâmetros $\gamma_{1,2}$ mais altos correspondem a uma economia com estágio de desenvolvimento tecnológico mais avançado.

Por sua vez, para controlar os efeitos de componentes aleatórios nos resultados da pesquisa de preços e do processo de inovação realizados pelas firmas, foi aplicada uma versão estilizada do método de Monte Carlo para cada regime de inovação: foram geradas 20 simulações para o cenário de baixo desenvolvimento tecnológico e 20 simulações para o de alto desenvolvimento tecnológico, variandose as sementes de inicialização de 1 a 20, no referido software. Destarte, os valores das variáveis representadas em cada período de tempo, nas figuras 1-12, são os valores médios das 20 simulações de cada período de tempo e dos respectivos regimes de inovação.

Quanto as principais condições iniciais, em cada simulação foi fixado que 100 firmas produtivas interagem ao longo de 500 períodos, que a taxa básica de juro $i$ é de $1 \%$, que o mark-up bancário inicial que evolui ao longo dos períodos é de $10 \%$, e que a demanda agregada que também evolui ao longo dos períodos é inicialmente de 200.000 unidades de produto. Por outro lado, em cada simulação foi atribuído como condição inicial para todas as 100 firmas, uma parcela de mercado de 0,01 , um preço de $\$ 2,00$, um lucro acumulado de $\$ 5.000,00$, e um mark-up inicial de $1 \%$ a $30 \%$, conforme uma distribuição uniforme. Em suma, todas as firmas são hedge e são praticamente idênticas inicialmente. A medida que as firmas diferenciam os preços o market share variará por uma porção $\beta$ da relação entre preço praticado e o preço médio da economia. Nesta simulação o valor do parâmetro $\beta$ é fixado em 0.1 , um valor que faz com que o grau de concentração de mercado aumente mas preserve um número relativamente grande de firmas no mercado, de modo a não terminar em um monopólio ou pequeno oligopólio. 
Tabela 1

Parâmetros - Baixo e alto desenvolvimento tecnológico

\begin{tabular}{l|c|c|c|c}
\hline Significado & Parâmetro & Equação & Baixo & Alto \\
\hline Taxa de cresc. da demanda & $\mathrm{g}$ & $(3)$ & 0.02 & 0.02 \\
\hline Variância da demanda & $\sigma_{1}^{2}$ & $(3)$ & 0.01 & 0.01 \\
\hline Mark-up firmas & $\rho$ & $(8)$ & 0.1 & 0.1 \\
\hline Ganhos de Market-share & $\beta$ & $(7)$ & 0.1 & 0.1 \\
\hline \% Lucros P\&D & $\varphi$ & $(8)$ & 0.05 & 0.05 \\
\hline CoefKaldor-Verdoorn & $\delta_{1}$ & $(11)$ & 0.02 & 0.02 \\
\hline Produtividade da imitação & $\delta_{2}$ & $(14)$ & 0.04 & 0.04 \\
\hline Spread mínimo dos bancos & $h^{m i n}$ & $(21)$ & 0.15 & 0.15 \\
\hline Variância da inovação & $\sigma_{2}^{2}$ & $(16)$ & 0.01 & 0.01 \\
\hline Prob. de ocorrência de inovação & $\gamma_{1}$ & $(15)$ & 0.1 & 0.3 \\
\hline Prob. de ocorrência de inovação & $\gamma_{2}$ & $(15)$ & 0.01 & 0.04 \\
\hline
\end{tabular}

\subsection{Níveis de desenvolvimento tecnológico mais baixo e alto}

O primeiro cenário macroeconômico é caracterizado pela baixa taxa de mudança tecnológica. Uma economia neste ambiente não é capaz de gerar inovações com muita frequência devido ao seu atraso tecnológico, portanto, até mesmo firmas com estratégias de inovação agressivas, como altos percentuais de lucros gasto em P\&D não conseguem inovar tanto quanto uma firma com a mesma estratégia operando numa economia mais desenvolvida. Este ambiente é capturado pelos parâmetros $\gamma_{1}$ e $\gamma_{2}$, os quais aumentam ou diminuem a probabilidade de ocorrência de uma inovação. No cenário 1, os valores de $\gamma_{1}$ e $\gamma_{2}$ são menores do que no cenário 2, como pode observado na Tabela 1 . Nesta simulação estamos assumindo que as firmas em cada um dos cenários são idênticas, e a única mudança que ocorre é no nível da indústria (aqui da economia) como um todo através das diferentes probabilidades de ocorrência de inovação, como dito.

\subsection{Cenário 1 - Nível de desenvolvimento tecnológico mais baixo}

No cenário 1, a taxa de crescimento do produto (CXT) em média é positiva e igual $2.07 \%$, porém apresenta pontos de reversão em que de positiva torna-se negativa. Por sua vez, a taxa de crescimento de preços(CMPE) é em média positiva no período de 1 a 500, porém apresenta declínio no período devido ao processo inovação e de difusão das inovações que ocorre por meio de processos de imitação. As firmas líderes tecnológicas e as firmas imitadoras com o objetivo de não perderem sua parcela de mercado, procuram reduzir seus preços ou, dado a competição via mark-up, evitar aumentos acima do mercado (Figura 1). 
Figura 1

Cenário 1 - BDT Crescimento(CXT) e Inflação(CPME)

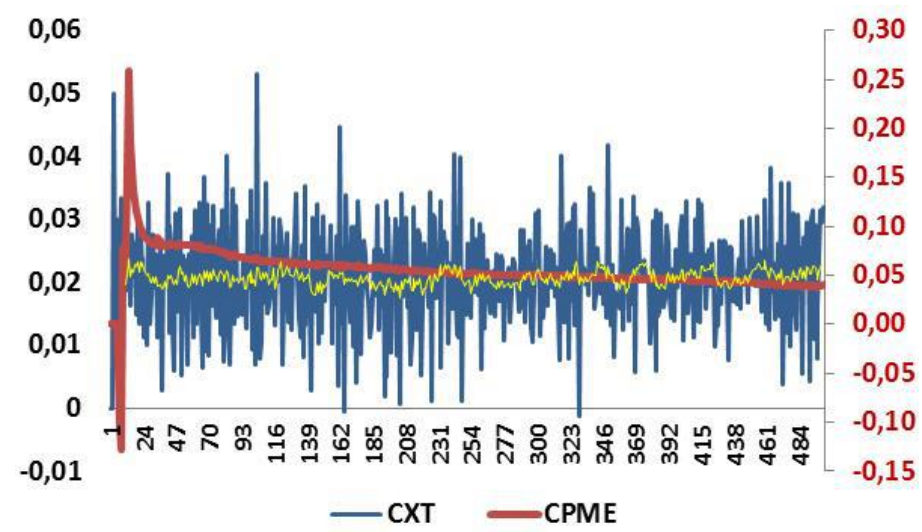

Figura 2

Cenário 1 - BDT Nível Tecnológico(AM) e Concentração(ICMHH)

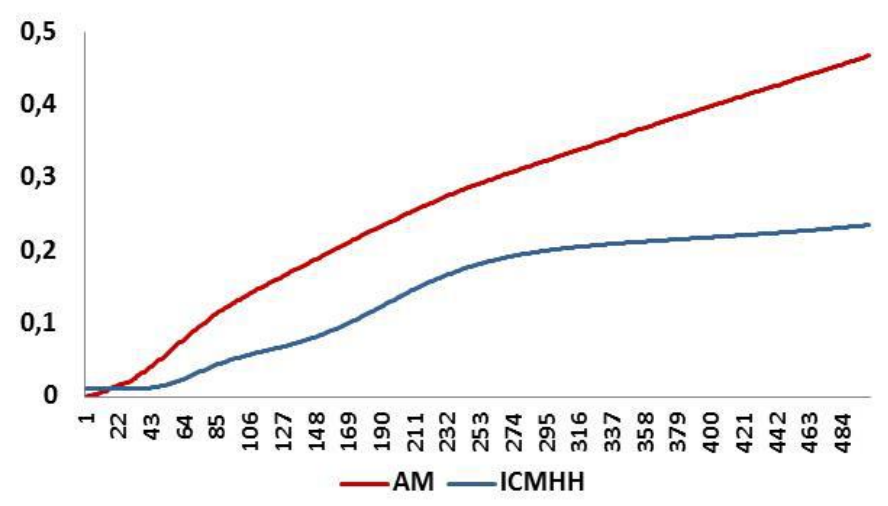

Ainda neste cenário, verifica-se alto grau de correlação positiva entre o nível tecnológico (AM), medida pela produtividade média do trabalho, e o nível de concentração de mercado (ICMHH) ${ }^{11}: 97.57 \%$. A mudança tecnológica ao elevar o nível de produtividade do trabalho das líderes tecnológicas, que em geral são firmas com postura financeira hedge, em uma taxa maior do que suas concorrentes, acaba aumentando sua competitividade-preço e a sua parcela de mercado (Figura 2). As firmas hedge que possuem a liderança tecnológica, conseguem mais do que compensar as elevações do salário nominal e real médio da economia e, destarte, sustentar aumentos de preços menores do que a firmas imitadoras. $O$ índice de concentração ICMHH no período 500 é igual a 0.2354 .

(11) ICMHH - Índice de Concentração de Mercado de Hirshman-Herfindal. 
De acordo com a Figura 3 o grau de fragilidade financeira $(\mathrm{GFF})^{12}$ aumenta com o crescimento da taxa de mudança tecnológica (CAM), medida pelo crescimento da produtividade do trabalho: a correlação é positiva e igual a $43.8 \%$, sendo esta propriedade uma característica comum aos dois cenários. O grau de fragilidade médio é igual a 0.95 e aumenta no final do período de simulação para 2,0 a medida que aumenta a taxa de crescimento do progresso tecnológico. O número de firmas com postura especulativa (PE) ou Ponzi (PP) são mostrados na Figura 4.

Figura 3

Cenário 1 BDT - Taxa de Mudança Tecnológica(CAM) e Grau de Fragilidade(GFF)

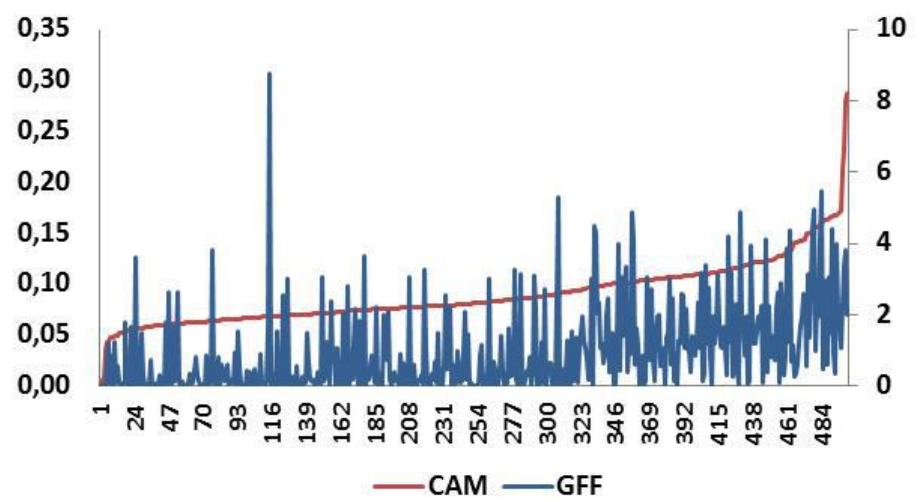

Figura 4

Cenário 1 BDT - Taxa de Mudança Tecnológica(CAM) e Risco das Firmas(PE,PP)

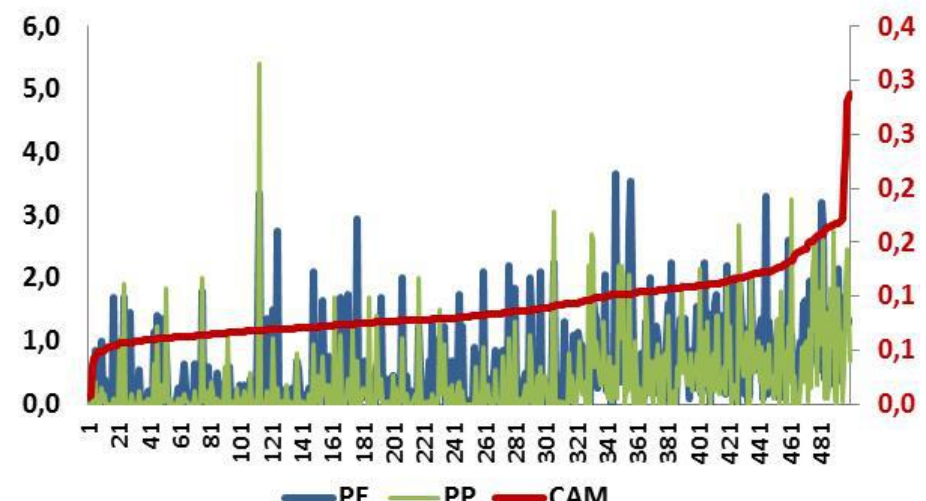

Assim, uma das fontes para a emergência espontânea de fragilidade financeira no sistema com a elevação da proporção de firmas ponzi e especulativas, é o que poderíamos chamar de efeito inovação: a mudança tecnológica ao causar a elevação

(12) GFF - O grau de fragilidade é medido pelo número de empresas especulativas e Ponzi, cujo máximo é 100 firmas. 
da produtividade do trabalho, reduz os custos de mão-de-obra e intensifica a competitividade-preço que, por sua vez, conduz a concentração de mercado a favor das firmas hedge e líderes tecnológicas, contribuindo para aumentar o grau de fragilidade financeira da economia. A firmas que não conseguem acompanhar as líderes acumulam prejuízos e ao recorrer ao financiamento para continuar na corrida tecnológica produzem instabilidade financeira.

Conforme a Figura 5, verifica-se também que a taxa de crescimento do produto (CXT) é positivamente correlacionado com o grau de fragilidade financeira (foi igual a 10.9\%). Se o crescimento da demanda efetiva for menor do que o crescimento da produção e da demanda esperada da firma, a sua receita operacional mais a sua receita financeira se houver, não cobrirá os seus custos de produção e de financiamento e, portanto, as firmas poderão sofrer uma alteração em sua postura financeira de hedge para especulativa ou até mesmo Ponzi aumentando a fragilidade do sistema, mesmo sem intensão de fazê-lo. As firmas com problemas de caixa recorrerem a financiamento e dado que o setor bancário reage endogenamente elevando a taxa de juro (spread bancário) o problema se intensifica precipitando a emergência de ciclos.

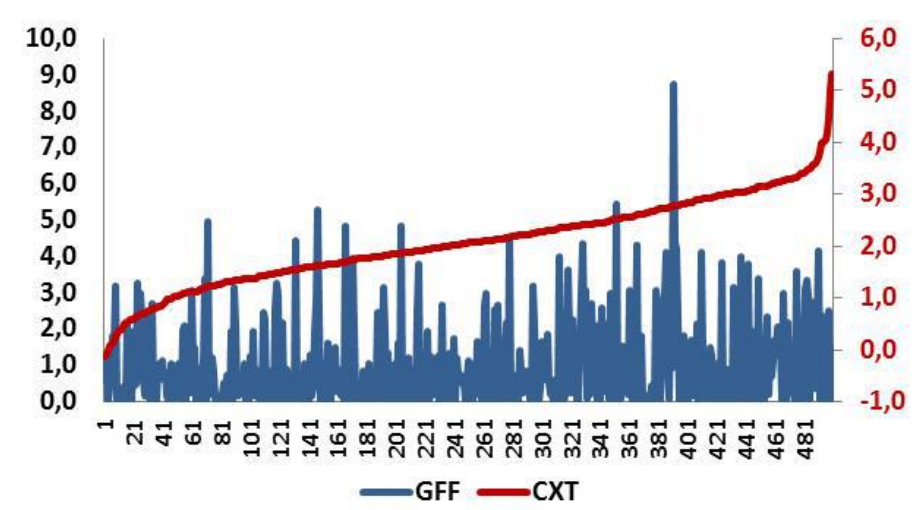

Por último, há uma correlação positiva entre o grau de fragilidade financeira(GFF) e os ciclos econômicos (ICE) ${ }^{13}$. De acordo com a figura 6 , verificase que existe no cenário 1 uma correlação positiva e igual a $19.4 \%$. O valor médio do GFF conforme já visto é igual a 0.95 , enquanto que o ICE nas 20 simulações é igual 0.2883 , o que implica 144.1 ciclos econômicos nos períodos de tempo de 1 a 500. Assim, quanto maior o grau de fragilidade financeira com forte presença de firmas com posturas financeiras especulativas e Ponzi, em qualquer período de

(13) ICE é o indicador de ocorrência de ciclos, medidos pela mudança de sinal na taxa de crescimento do produto $C X T$, seu valor é igual a 0 para ausência de mudança de sinal na taxa de crescimento do produto e igual a 1 , se o crescimento tornar-se negativo. 
tempo $t$, maior será a possibilidade no período de tempo $t+1$, da emergência de um ponto de reversão ou do ciclo econômico e, por extensão, quanto maior a percentagem de firmas especulativas ponzi maior também será o efeito de redução no crescimento pelo excesso de ciclos com fases negativas.

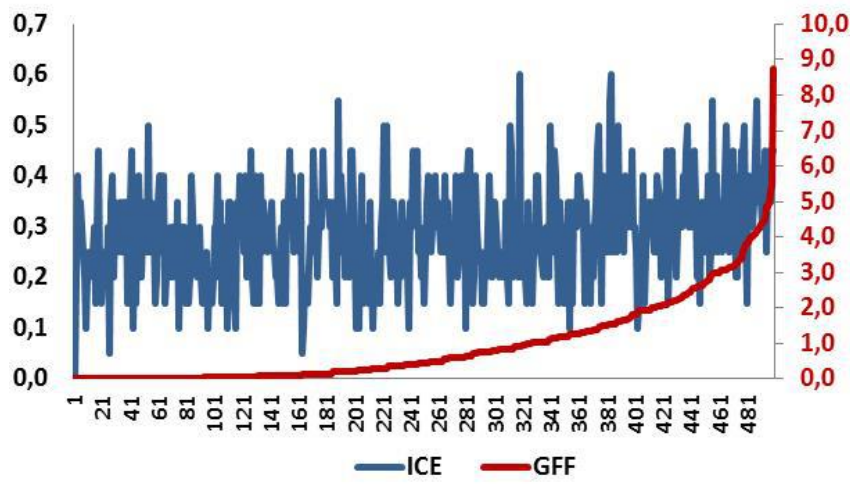

\subsection{Cenário 2 - Nível de desenvolvimento tecnológico mais alto}

O segundo cenário macroeconômico é caracterizado pela alta probabilidade de ocorrência de uma inovação. Uma economia neste ambiente é capaz de gerar mais inovações, por exemplo, devido ao maior desenvolvimento tecnológico acumulado e a complexidade atingida pelo seu sistema produtivo. Neste caso as firmas com estratégias de inovação agressivas, como altos percentuais de lucros gasto em P\&D, terão um desempenho maior em termos de geração de inovação, do que se operassem numa economia menos desenvolvida. Este ambiente de alta inovação é capturado pelos parâmetros $\gamma_{1}$ e $\gamma_{2}$, os quais aumentam a probabilidade de ocorrência de uma inovação, isto é, aumentam $P_{i, t}^{I N}$ conforme a equação (15). A questão aqui é se esta mudança nos parâmetros terá consequências diferentes daquelas observadas no cenário 1, de baixo desenvolvimento tecnológico. Uma das questões relevantes que pode ser respondida, a qual é objeto de muitos estudos sobre as relações entre ciclo e crescimento e finanças, é o comportamento da economia e do sistema financeiro em uma economia mais inovativa. $\mathrm{O}$ que diferencia o cenário 2 são os valores maiores de $\gamma_{1}$ e $\gamma_{2}$, os quais aumentaram 3 e 4 vezes, respectivamente, conforme Tabela 1 .

Assim, como ocorre com o primeiro cenário, a taxa de crescimento do produto (CXT) mostrada na Figura 7 em média é positiva e igual a 2.09\%, porém apresenta períodos de reversão tornando-se negativa. Por sua vez, a taxa de crescimento de preços (CMPE) é inicialmente positiva devido aos lucros de 
monopólio do inovador e a rápida concentração de mercado, porém com o processo de difusão das inovações por meio de processos de imitação, ocorre a queda da taxa de crescimento de preços que torna-se negativa. Ou seja, as firmas líderes tecnológicas e as firmas imitadoras no sentido de não perder sua parcela de mercado, são forçadas a reduzir seus preços para adaptar-se à maior taxa de inovação.

Figura 7

Cenário 2 - ADT Crescimento(CXT) e Inflação(CPME)

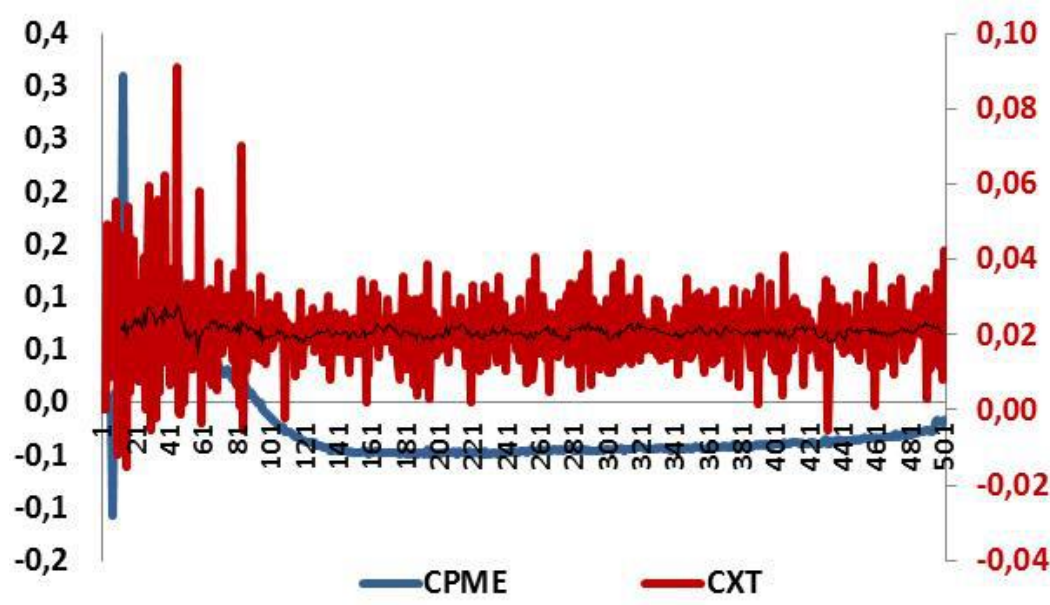

Figura 8

Cenário 2 - ADT Nível Tecnológico(AM) e Concentração(ICMHH)

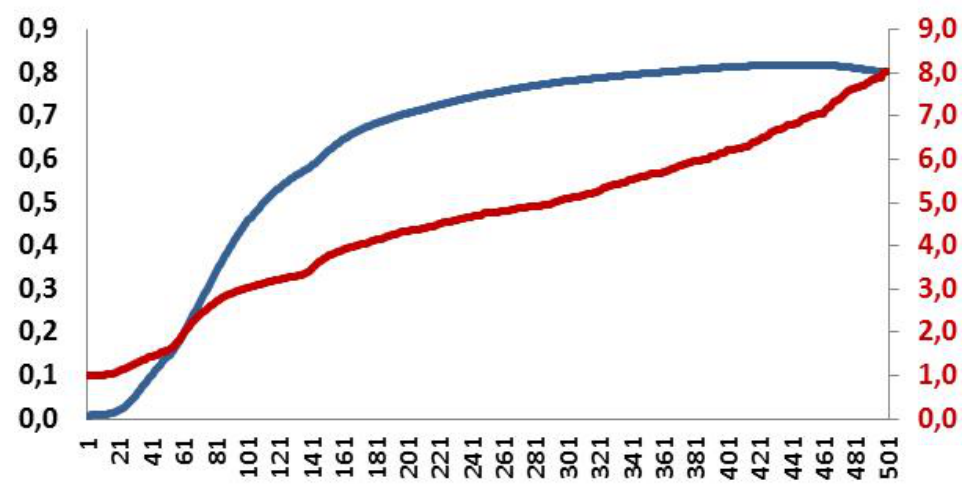

$\longrightarrow \mathrm{ICMHH} \longrightarrow \mathrm{AM}$

No cenário 2, há também um alto grau de correlação positiva entre o nível tecnológico (AM) e o nível de concentração de mercado (ICMHH): 90.3\%. Como a capacidade ou produtividade do trabalho em atividades inovativas dado pelo parâmetro $\gamma_{1}$ e o efeito da cumulatividade da mudança tecnológica dado pelo 
parâmetro $\gamma_{2}$ sobre a probabilidade de inovação, são maiores do que no cenário 1, a taxa de mudança tecnológica é também maior, destarte, o processo de diferenciação entre as firmas ser mais intenso, conduzindo a um nível maior de concentração de mercado a favor das firmas líderes tecnológicas que em, em geral, são as firmas hedge que aplicam parte de lucros acumulados em gastos de pesquisa e desenvolvimento tecnológico (figura 8). O índice de concentração HirshmanHerfindall (ICMHH) no período 500 é igual a 0.802 .

A maior facilidade de gerar inovações neste cenário 2 não gera uma tendência de maior concorrência entre as firmas, desde que no processo de aprendizado formal via $\mathrm{P} \& \mathrm{D}$, há presença de componentes cumulativos do aprendizado tecnológico captada pela probabilidade de inovação ser também determinada pelos resultados tecnológicos obtidos em períodos passados: a probabilidade de inovação em qualquer período depende dos resultados tecnológicos obtidos em períodos passados. Além disso, a suposição de que a tecnologia a ser imitada possui componentes locais, tácitos e específicos, limita a capacidade de imitação da firma retardatária, a qual é uma função decrescente da distância tecnológica em relação as firmas líderes tecnológicas.

Assim como ocorre com o primeiro cenário, de acordo com as Figuras 9 e 10, o grau de fragilidade financeira (GFF) aumenta com o crescimento da taxa de mudança tecnológica (CAM): a correlação é positiva e igual a $23.4 \%$, sendo esta propriedade uma característica comum aos dois cenários. Na medida que a dinâmica tecnológica é maior neste cenário 2 , o grau de fragilidade média também é maior e igual a 3.3. Este resultado corrobora uma importante conclusão relacionada à discussão teórica realizada na seção 1: a de que o aumento da taxa de inovação ou progresso tecnológico implica simultaneamenteuma fragilidade financeira das firmas e instabilidade maiores no sistema.

\section{Figura 9}

Cenário 2 ADT - Taxa de Mudança Tecnológica(CAM) e Grau de Fragilidade(GFF)

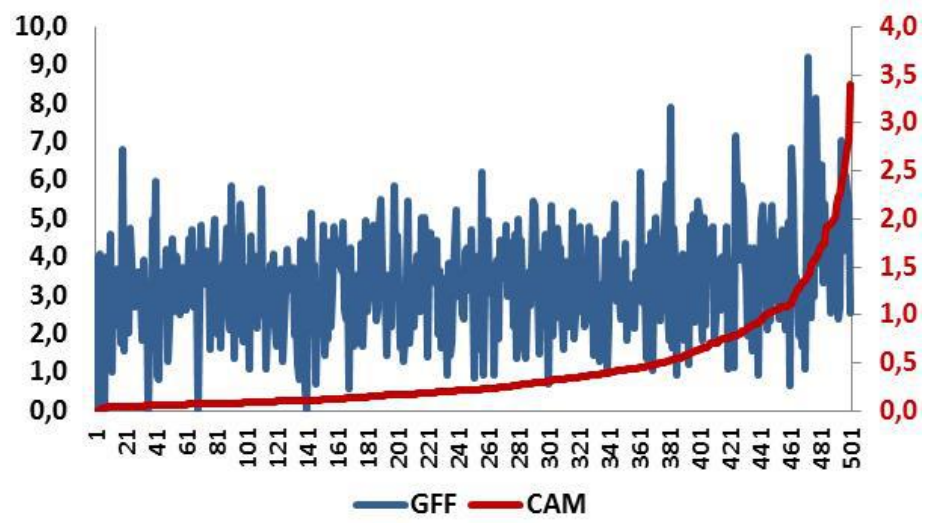


Figura 10

Cenário 2 ADT - Taxa de Mudança Tecnológica(CAM) e Risco das Firmas(PE,PP)

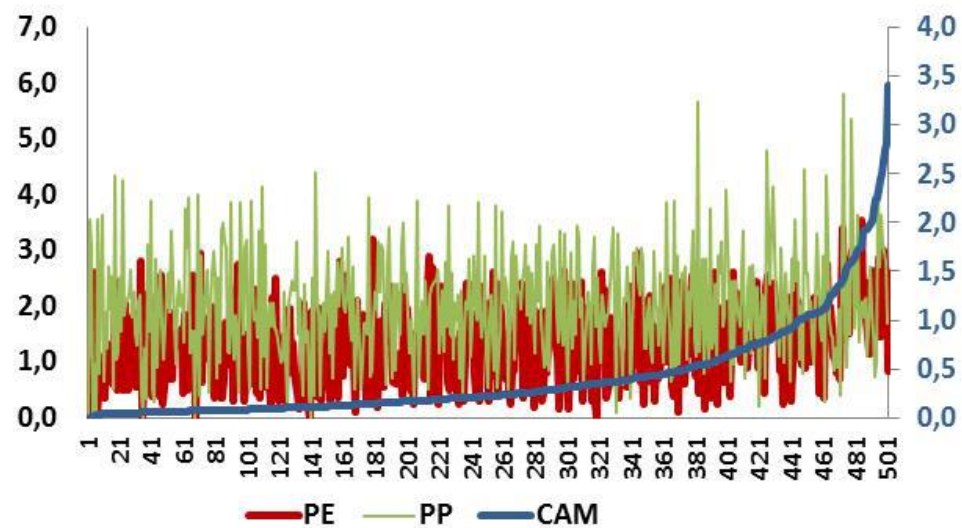

Novamente neste cenário 2, conforme a Figura 11, verifica-se que a taxa de crescimento do produto (CXT) exerce efeito positivo sobre o grau de fragilidade financeira, com a diferença de que o grau de correlação é positivo e igual a $28.5 \%$, maior do que no cenário 1.

Por fim, no cenário 2 há uma maior correlação entre o grau de fragilidade financeira(GFF) e o ciclo econômico (ICE), desde que o grau de correlação linear é positivo e igual a $46.8 \%$ como pode ser visto na figura 12 . O valor médio do GFF conforme já visto é igual a 3.34 enquanto que do ICE nas 20 simulações é igual 0.295, o que implica 147.1 ciclos econômicos nos períodos de tempo de 1 a 500 . O número de ciclos aumenta em relação ao regime de baixo desenvolvimento tecnológico.

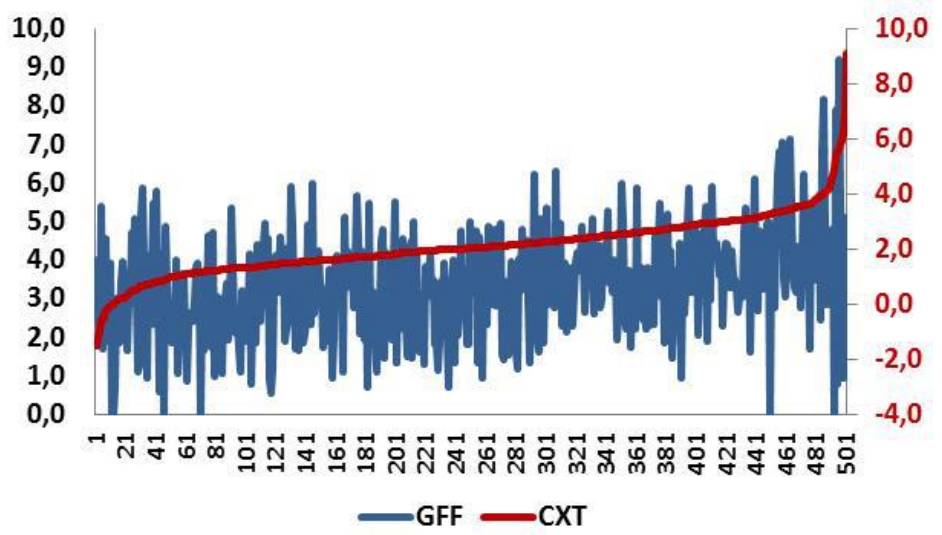


Figura 12

Cenário 2 ADT - Grau de Fragilidade(GFF) e Ciclo(ICE)

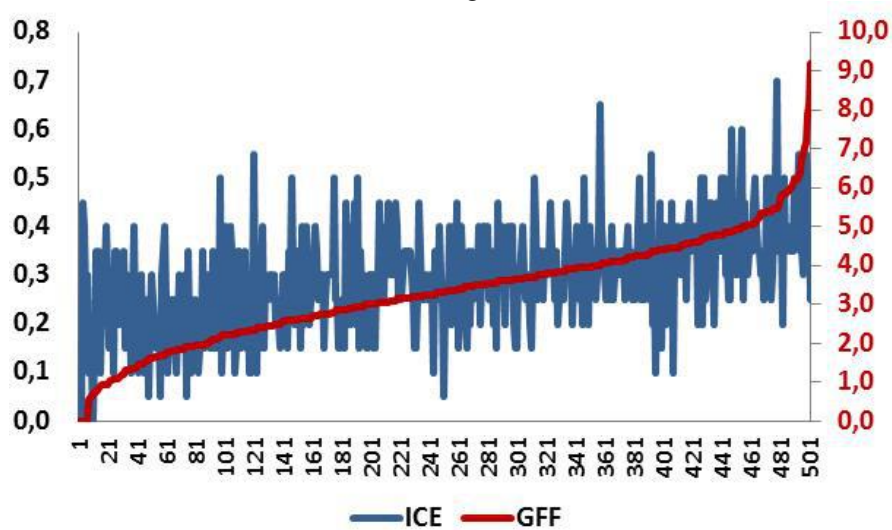

\subsection{Relações de causalidade - testes econométricos}

Embora o modelo seja construído a partir de equações em diferenças finitas, em geral com um lag de defasagem, a interação das firmas entre si e das suas respostas adaptativas ao ambiente macroeconômico pode gerar relações de causalidade distintas daquelas contidas na estrutura matemática destas equações. Para avaliar estas relações de causalidade, que emergem de relações complexas, apresentamos na tabela 2 os resultados de testes de causalidade executados a partir dos dados das 20 simulações apresentadas anteriormente.

Para testar as conexões entre as variáveis $C A M$ e $G F F$ e $C X T$ e $G F F$ foram criadas as variáveis $G F F C X T$ e $G F F C A M$ classificando-se os valores de $G F F$, do menor para o maior valor das variáveis $C X T$ e $C A M$, respectivamente. Nos testes de raiz unitária, para escolher a ordem das defasagens foi aplicado os critérios informação de Akaike modificado e Schwarz-SC. Uma vez satisfeitos os critérios de raiz unitária e cointegração executou-se os testes de causalidade no sentido de Granger. Nos testes de cointegração e de causalidade a seleção da quantidade de defasagens foi realizada aplicando-se os critérios informação de Akaike, HannanQuinn e Bayesiano.

Estamos interessados, nesta análise, em testar as relações de causalidades entre fragilidade financeira, mudança tecnológica e ciclo econômico. A estrutura matemática do modelo poderia facilmente induzir a uma relação de causalidade unidirecional entre estas variáveis. Mas surpreendente estas relações de causalidade não coincidem com a estrutura matemática das equações e mais ainda, se alteram quando se passa de um caso de uma economia de mais baixo desenvolvimento tecnológico (BDT) para mais alto (ADT). Isto pode ser observado na parte final da Tabela 2 que mostra os teste de causalidade de Granger. 
Tabela 2

Testes econométricos de relações de causalidade

\begin{tabular}{|c|c|}
\hline \multicolumn{2}{|c|}{ Raiz Unitária DF-GLS ao Nível de Significância de 5\% } \\
\hline BDT & ADT \\
\hline $\begin{array}{l}C X T, C A M, G F F C A M, G F F \text { e ICE } \\
\text { são variáveis com raiz unitária I(1) e GFFCXT é } \\
\text { uma variável } \mathrm{I}(0)\end{array}$ & $\begin{array}{l}C X T, G F F C X T, C A M, G F F C A M, G F F \text { e ICE } \\
\text { são variáveis com raiz unitária } \mathrm{I}(1)\end{array}$ \\
\hline \multicolumn{2}{|c|}{ Vetores de Cointegração de Johansen ao Nível de Significância: 5\% } \\
\hline BDT & ADT \\
\hline$G F F=-0,8424+21,4462 * C A M$ & $G F F=3,0859+62,9739 * C A M$ \\
\hline Não há cointegração entre $C X T$ e $G F F$ & $G F F=2,0856+57,9250 * C X T$ \\
\hline$I C E=-1,2449+0,0697 * G F F$ & $I C E=-1,8249+0,4605^{*} G F F$ \\
\hline \multicolumn{2}{|c|}{ Teste de Wald para Causalidade de Granger ao Nível de Significância de 5\% } \\
\hline BDT & ADT \\
\hline Causalidade bidirecional entre $C A M$ e $G F F$ & Causalidade unidirecional de $C A M$ para $G F F$ \\
\hline Ausência de causalidade entre $C X T$ e $G F F$ & Causalidade bidirecional de $C X T$ para $G F F$ \\
\hline Causalidade unidirecional de $G F F$ para $I C E$ & Causalidade bidirecional entre $I C E$ e $G F F$ \\
\hline
\end{tabular}

As relações de causalidade resultantes mostram que no cenário de alto desenvolvimento tecnológico (ADT) a mudança tecnológica contribui para aumentar o grau de fragilidade financeira da economia, enquanto que no cenário de baixo desenvolvimento tecnológico (BDT) a causalidade é bidirecional entre ambos. Outro resultado econométrico é que no cenário ADT, a causalidade é bidirecional entre o crescimento do produto e o grau de fragilidade financeira, enquanto que no cenário de BDT verifica-se a ausência de causalidade entre ambos. Por último, verifica-se que no cenário BDT quanto maior o grau de fragilidade financeira, sobretudo com a forte presença de firmas Ponzi com expectativas de vendas negativas, maior a frequência e a amplitude de ciclos econômicos, enquanto que no cenário ADT a causalidade é bidirecional entre ambos.

A complexidade do modelo não permite avançar muito na direção da explicação dos mecanismos subjacentes aos resultados, porém pode-se esclarecer que no cenário 2-ADT, em linhas gerais, as conexões entre os regimes de financiamento e a taxa de mudança tecnológica, entre os regimes de financiamento e a taxa de crescimento do produto, e entre os ciclos econômicos e o grau de fragilidade financeira, são mais intensas do que no cenário 1-BDT; e ainda o grau de fragilidade financeira interage tanto com a taxa de mudança tecnológica quanto com a taxa de crescimento do produto. A nossa interpretação teórica é que a maior facilidade de gerar inovações e de criação de assimetrias tecnológicas a favor das firmas hedge e líderes tecnológicas, aumenta o peso na dinâmica tecnológica agregada do aprendizado tecnológico via gastos em $\mathrm{P} \& \mathrm{D}$, em detrimento do aprendizado na produção e na imitação: a cumulatividade do progresso técnico possui maior intensidade em determinar a probabilidade de inovação do que no 
cenário 1-BDT. Este resultado, por outro lado, contribui para alterar as relações de causalidade entre a taxa de mudança tecnológica e o grau de fragilidade financeira, entre a taxa de crescimento do produto e o grau de fragilidade financeira, e os ciclos econômicos e o grau de fragilidade financeira.

\section{Conclusão}

A teoria econômica do crescimento e ciclo econômico avançou em duas frentes nos últimos anos. Em uma delas integrando tecnologia e na outra finanças. Dificuldades consideráveis surgem na tentativa de construir uma teoria que integre estes dois componentes fundamentais de uma economia capitalista para descrever o processo dinâmico de crescimento sujeito a ciclos. Realizar tal empreendimento por meio da construção de modelos agregados baseados em agentes representativos com soluções analíticas constitui-se em uma tarefa difícil, não tanto pelo lado da formalização da teoria, mas pelo lado da fundamentação microeconômica. No caso da abordagem agregada, o crescimento e o padrão cíclico somente podem ser obtidos assumindo-se a priori que tal dinâmica preexiste no sistema econômico e assim, arbitrando-a em uma equação agregada que representa, no nível microeconômico, o mesmo padrão comportamental para todos os agentes. No entanto, como procurouse descrever, a emergência de um padrão de crescimento e ciclo depende muito da interação entre os agentes heterogêneos e ocorre exatamente pela diferenciação ou heterogeneidade forjada pela inovação que se acumula nos agentes ao longo do tempo e na sua relação com o sistema bancário, o qual reage também endogenamente. $\mathrm{O}$ que torna o problema teórico da integração entre o crescimento e o ciclo, a inovação e as finanças, uma tarefa desafiadora, para qualquer abordagem teórica e metodológica, é o excesso de endogeneidade nas várias partes (capturadas por variáveis) do sistema. $\mathrm{Na}$ abordagem macroeconômica baseada em agentes representativos, muitas vezes é preciso fazer suposições simplificadoras, em geral considerando exógena uma variável que deveria ser endógena, com vistas a obter uma solução analítica manipulável algebricamente. Este procedimento, muito útil em várias situações, produz no presente caso, sérias restrições para descrever e formalizar em um modelo algébrico as origens da instabilidade e fragilidade das economias capitalistas.

Este obstáculo de endogenia pode ser transposto com relativa facilidade com uma abordagem baseada em agentes heterogêneos. No nível microeconômico, os agentes seguem suas rotinas próprias de busca de lucros, ajustam suas estratégias de fixação preço, e esforçam-se continuamente em inovar de diferentes maneiras (learning by doing, imitação e inovação propriamente dita). O sistema bancário é sensível e reage aos resultados colhidos pelas firmas ao longo dos seus sucessos e fracassos, materializados no fluxo de caixa positivo ou negativo das firmas. Os agentes (firmas) não possuem em seu "código genético", se pudermos usar esta 
metáfora, o comportamento cíclico. O crescimento e o ciclo não podem ser considerados uma propriedade ou característica do agente, muito pelo contrário, eles só são visíveis como manifestação macroeconômica de um comportamento complexo, posto que interativo, que ocorre no nível do agente. Os agentes apenas seguem suas rotinas individuais, atentos, evidentemente a sinais de mercado. São as interações complexas, diretas e indiretas, entre os agentes que produzem estes fenômenos.

Nas simulações apresentadas procurou-se mostrar que é possível controlar e reproduzir teoricamente padrões macroeconômicos dinâmicos e complexos oriundos da integração dos fenômenos do crescimento e do ciclo com a inovação e as finanças. E mais do que isso, ao invés de impor aprioristicamente tal comportamento, obtemos tal resultado de uma descrição mais realista e simples do comportamento microeconômico no nível do agente.

Resumindo os principais resultados, procurou-se mostrar que a fragilidade financeira de uma economia capitalista é maior em regimes tecnológicos mais inovativos. A competição tecnológica, schumpeteriana, conduz a um processo de diferenciação das firmas, algumas crescendo mais e outras até desaparecendo do mercado. Durante esta dinâmica microeconômica, emergem no nível macroeconômico ciclos que são mais intensos e frequentes quanto maior for a capacidade de inovação do sistema econômico. De fato mostramos na seção 2 que o regime $\mathrm{ADT}$, de alto desenvolvimento tecnológico, possui um grau de fragilidade financeira maior do que o regime BDT, de baixo desenvolvimento tecnológico, ao mesmo tempo que possui maior frequência de ciclos de pequena duração, tornando uma economia mais inovativa, também mais instável.

É importante destacar que esta instabilidade decorreda junção e da interação entre partes do sistema no nível do agente, com as firmas interagindo fortemente com outras firmas, com as firmas interagindo com o cenário macroeconômico geral por meio de ajuste de expectativas e de variações da taxa de juros realizadas, também endogenamente, pelo setor bancário. O modelo complexo de crescimento e ciclo econômico formulado e explorado no presente artigo realiza avanços em relação aos estes trabalhos de Gallegati, Giulioni e Kichiji (2006) e Lima e Freitas (2007b).

Os principais avanços teóricos em relação aos modelos de Gallegati, Giulioni e Kichiji (2006) e Lima e Freitas (2007b) consistem em, primeiro, tornar endógena a mudança tecnológica representada pela taxa de crescimento da produtividade do trabalho das firmas e, segundo, tornar endógena a taxa de crescimento do salário nominal e real da economia que, por sua vez, passam a ser determinados por mecanismos de aprendizado formal e informal ao nível das firmas. Esta simples mudança produz efeitos importantes na dinâmica da economia e é o que permite avançar na formulação de uma teoria integrada do crescimento e do ciclo 
econômico com a mudança tecnológica e o financiamento bancário. Ao tornar endógena a mudança tecnológica e a dinâmica de salários nominais e reais, tornouse possível analisar comparativamente a dinâmica coevolucionária de diferentes regimes de inovação e de regimes de financiamento e suas implicações dinâmicas para o processo de crescimento cíclico.

\section{Referências bibliográficas}

ANGBAZO, L. Commercial bank net interest margins, default risk, interest risk, and off-ballance sheet banking.Journal of Banking and Finance, v. 21, 1997.

ARROW,KENNETH J.The economics implicatons of learning by doing.Review of Economic Studies, v. 29, p. 155-173, 1962.

ARROW, KENNETH J. Economic welfare and the allocation of resources for invention. In:COLLECTED papers of Kenneth J. Arrow.V. 5: Production and capital, 1985. Cambridge, MA:Harvard University Press, 1962.

BENCIVENGA, VALERIE R.; SMITH, BRUCE D.Financial intermediation and endogenous growth.The Review of Economic Studies, v. 58, n. 2, p. 195-209, Apr. 1991.

BOYD,JOHN H.; SMITH, BRUCE D., Intermediation and the equilibrium allocation of investment capital: Implications for economic development. Journal of Monetary Economics, v. 30, n. 3, p. 409-432, 1992.

BROCK, P.; ROJAS-SUAREZ, L.Understanding the behavior of bank spreads in Latin America.Journal of Development Economics, v. 63, 2000.

BROWN, JAMES R.; FAZZARI,STEVEN M.; BRUCE, Petersen. Financing innovation and growth: cash flow, external equity, and the 1990s R\&D boom.The Journal of Finance, v. 64, n. 1, p. 151-185, 2009.

CAMERON, Rondo E.Banking in the early stages of industrialization: astudy in comparative economic history. New York:Oxford University Press, 1967.

DE LA FUENTE, A.; MARIN, J.M.Innovation, bank monitoring, and endogenous financial development.Journal of Monetary Economics, v. 38, p. 269-301, 1996.

DOSI,G.;FREEMAN,C.;FABIANI,S. The process of economic development: introducing some stylized facts and theories on technologies, firms and institutions.Industrial and Corporate Change, v. 3, p. 168-203, 1994.

ÉRDI, Péter. Complexity explained. Berlin, Heidelberg:Springer-Verlag, 2008.

GALETOVIC, Alexander. Specialization, intermediation and growth.Journal of Monetary Economics, v. 38, n. 3, p. 549-559, 1996. 
GALLEGATI, M.; GIULIONI, G.;KICHIJI, N.Complex dynamics and financial fragility in an agent-based model.Advances in Complex Systems, v. 6, n. 3, p. 267282, 2003.

GEISENDORF, Sylvie. The influence of innovation and imitation on economic performance.Economic Issues, v. 14, n. 1, 2009.

GOLDSMITH, Raymond W.Financial structure and development.New Haven, Conn.: Yale University Press, 1969.

GREENWOOD, J.; JOVANOVIC, B.Financial development, growth, and the distribution of income.Journal of Political Economy, v. 98, p. 1076-1107, 1990.

GRIBBIN, J.Deep simplicity: bringing order to chaos and complexity. London:Random House, 2005.

JUNG, Woo S.Financial development and economic growth: international evidence.Economic Development and Cultural Change, v. 34, p. 333-346, Jan. 1986.

KALDOR, Nicholas.Capital accumulation and economic growth.In:LUTZ,F. A.;HAGUE,D. C. (Ed.).The theory of Capital.New York:St. Martin's Press,1961. p. $177-222$.

KALDOR, Nicholas.The scourge of monetarism.Oxford:Oxford University Press, 1982.

KALDOR, Nicholas.How monetarism failed.Challange, v. 28, n. 2, p. 4-13, May/Jun. 1985.

KING, Robert G.; LEVINE, Ross.Financial, entrepreneurship, and growth: theory and evidence.Jounal of Monetary Economics, v. 32, p. 513-542, 1993.

LEONTIEF, Wassily;Strout, A.Multiregional input-output analysis.In BARNA,T. (Ed.).Structural interdependence and economic development. London, UK:St. Martin Press,1963. p. 243-259.

LEVINE, Ross. Stock markets, growth, and tax policy.The Journal of Finance, v. 46, n. 4, p. 1445-1465, Sept. 1991.

LEVINE, Ross. Finance and growth: theory and evidence. In AGHION,P.;DURLAUF,S. (Ed.).Handbook of economic growth. Amsterdam: North-Holland Elsevier, 2005.

LIMA, Gilberto T.;FREITAS, G.G.Systemic financial fragility as emergent property.In: GEYER,R.;BOGG;J.(Ed.). Complexity, science and society. Oxford, UK: Radcliffe Publishing, 2007a.

LIMA, Gilberto T.:FREITAS, G.G.Debt financing and emergent dynamics of a financial fitness landscape. Manuscript for presentation at the agent-based 
economics sessions at the Eastern Economic Association Meetings. New York City, Feb. 23-25, 2007 b.

LUCAS, Robert L. On the mechanism of economic development.Journal of Monetary Economics, v. 22, p. 3-42, 1988.

MCKINNON, Ronald I.Money and capital in economic development.Washington:Brookings Institute, 1973.

MERTON, R.C.; BODIE, Z.A conceptual framework for analyzing the financial environment. In:CRANE, D.B. et al.The global financial system: afunctional perspective. Boston, Massachussets: Harvard Business School Press, 1995. p. 3-31.

MERTON,R.C.A functional perspective of financial intermediation.Financial Management, v. 24, n. 23-41, 1995.

MINSKY, H.Can it happen again? Essays on instability and finance.New York: M. E. Sharpe, 1982.

MOORE, Basil.Horizontalists and verticalists: the macroeconomics of credit money. Cambridge:Cambridge University Press, 1988.

MORALES, María F.Financial intermediation in a model of growht through creative destruction.Macroeconomic Dynamics, v. 7, n. 3, p. 363-393, 2003.

NELSON, Richard R.; PHELPS, Edmund S.Investment in humans, technological diffusion, and economic growth.American Economic Review, v. 56, p. 69-75, 1966.

NELSON, Richard R.; WINTER, Sidney. An evolutionary theory of economic change. Harvard: Harvard University Press, 1982.

ROBINSON, Joan. The generalization of the general theory.In: THE RATE of interest and other essays. London:Macmillan, 1952.

SAINT-PAUL, Gilles. Technological choice, financial markets and economic development.European Economic Review, v. 36, n. 4, p. 763-781, 1992.

SAUNDERS, A.; SCHUMACHER, L.The determinants of interest rate margins: an international study.Journal of International Money, v. 19, 2000.

SEGERSTROM, Paul S.Innovation, imitation, and economic growth.Journal of Political Economy, v. 99, n. 4, p. 807-827, 1991.

SHAW, Edward S.Financial deepening in economic development.New York:Oxford University Press, 1973.

VALENTE, Marco. Laboratory for simulation development - LSD.Pisa, Italy: Laboratory of Economics and Management - LEM, 2008 (Working Papers, 2008/12). 
VALENTE, M.; ANDERSEN, E.S.A hands-on approach to evolutionary simulation: Nelson and Winter models in the laboratory for simulation development. The Eletronic Journal of Evolutionary Modeling and Economic Dynamics, 2002.

VERDOORN, J. P.On the factors determining the growth of labor productivity. In PASINETTI,L. (Ed.). Italian economic papers. Oxford: Oxford University Press, 1949.v. II.

WALDROP, M.Complexity: the emerging science at the edge of order and chaos.New York:Touchstone, 1992. 